\title{
A PROTECTIONIST BIAS IN MAJORITARIAN POLITICS*
}

\author{
Gene M. Grossman and Elhanan Helpman
}

\begin{abstract}
We develop a novel model of campaigns, elections, and policy-making in which the ex ante objectives of national party leaders differ from the ex post objectives of elected legislators. This generates a distinction between "policy rhetoric" and "policy reality" and introduces an important role for "party discipline" in the policy-making process. We identify a protectionist bias in majoritarian politics. When trade policy is chosen by the majority delegation and legislators in the minority have limited means to influence choices, the parties announce trade policies that favor specific factors, and the expected tariff or export subsidy is positive. Positions and expected outcomes monotonically approach free trade as party discipline strengthens.
\end{abstract}

\section{INTRODUCTION}

In a democracy, the majority rules. Often, this means that the policies enacted by elected governments reflect the preferences of some citizens more than those of others. This feature of democracy-commonly known as "tyranny of the majority"arises in institutional settings in which elected officials represent disproportionately the interests of their own constituents and electees who represent the minority have limited means to influence policy.

In this paper we argue that tyranny of the majority imparts a protectionist bias to democratic politics. This is so even when the average citizen covets free trade and when every citizen has an equal probability of being represented in the policy-making process. By "protection" we mean policies that favor quasi-fixed factors of production. Thus, protection in our parlance refers both to tariffs that shield import-competing industries from foreign competition and subsidies that promote exports. The bias refers to the average or expected policy outcome.

We focus on majoritarian systems in which elected legislators represent geographic regions. The existence of a protectionist bias requires only that (i) national party leaders cannot fully commit their candidates to adopt particular policies if elected, (ii) mem-

* We are grateful to Robert Barro, Avinash Dixit, Torsten Persson, Thomas Romer, Andrei Shleifer, and two anonymous referees for helpful discussions and suggestions and to Itay Fainmesser and Mihai Manea for outstanding research assistance. We acknowledge with thanks the support of the National Science Foundation (SES 0211748) and the US-Israel Binational Science Foundation (2002132). Part of Helpman's work was done when he was Sackler Visiting Professor at Tel Aviv University.

() 2005 by the President and Fellows of Harvard College and the Massachusetts Institute of Technology.

The Quarterly Journal of Economics, November 2005 
bers of the majority delegation in the legislature give disproportionate weight to residents of their own districts when setting policy, and (iii) members of minority delegations cannot fully compensate those in the majority to induce a nationally efficient policy choice. We believe that these conditions are met in most, if not all, majoritarian political systems.

To establish our point and to study the bias, we develop a novel, three-stage model of political campaigns, district elections, and legislative policy-making. In our model we distinguish between the ex ante objectives of political parties and the ex post objectives of elected legislators. Each national party aims to capture a majority of the seats in the legislature in order to pursue its ideological agenda. The parties announce positions on the trade policy issues that are intended to garner support from voters in the various districts. The voters recognize that while the campaign promises may influence the subsequent legislative deliberations, they do not fully bind the actions of the elected politicians. After the platforms are announced, the heterogeneous voters in each district elect a single representative to the national legislature. Each voter casts his ballot to maximize his expected utility in anticipation of the prospective actions of the elected body (which will depend on its composition) and in the face of uncertainty about electoral outcomes in districts other than his own. Finally, after the election results are in, the legislators in the majority delegation set policy to maximize their joint political welfare, which reflects both the well-being of their own constituents and the political costs that might ensue from any failure to deliver on their party's campaign promises. Our model thus incorporates a distinction between "policy rhetoric" (that which is announced by the parties as their legislative intentions) and "policy reality" (that which is enacted by the elected legislative body).

We show in this context that a protectionist bias results whenever districts differ in their ownership shares of the industry-specific factors, industry outputs respond positively to prices, and parties cannot perfectly precommit the actions of the elected legislature. We proceed to investigate the determinants of the size of the bias, one important element of which is the extent to which a party can induce its members to carry through on its campaign promises. As we shall see, the geographic distribution of the industry-specific factors also plays a central role.

Our paper fits well into the burgeoning literature on the 
comparative politics of economic policy, a literature that links political institutions to economic policy outcomes. For example, Persson, Roland, and Tabellini [2000] compare redistributive policies in presidential versus parliamentary systems, while MilesiFerretti, Perotti, and Rostanga [2002] study transfer payments and provision of local public goods under different voting rules. In this paper and in a companion piece on the provision of local public goods [Grossman and Helpman 2005], we consider the ability of political parties to precommit to specified policies to be a distinct institutional feature of the political system. At one extreme, a party may be able to announce a platform to which its members will be fully bound if elected. At the opposite extreme, the elected representatives may disregard entirely the promises made by their party during the campaign and instead pursue only their ex post, parochial objectives. In between these extremes, the extent to which the political parties can tie the hands of the politicians who are subsequently elected will depend on institutional characteristics of the political regime, such as the role of the national party in financing regional campaigns, in allocating the perquisites of election, and in choosing candidates for higher office.

In what follows, we shall refer to the institutional variation that is of interest to us as differences in "party discipline." We acknowledge that this term most often is used by political scientists and others to mean the extent to which parties (or the leaders of a legislative delegation) can induce members to toe the current party line. Here we use the term slightly differently to refer to a party's ability to induce ex post adherence to a preannounced position. ${ }^{1}$ The parties face a "commitment problem," because their ex ante incentives to promise trade policies that will help them win election may diverge from the more parochial concerns that elected legislators will confront ex post. The extent of the commitment problem will depend on the political environment and in particular on the instruments that the parties have to reward those who carry through on its promises and the sanctions available to punish those who do not.

1. Other terms that have been suggested to us include "the extent of commitment to party platforms" and "platform fidelity." The former is descriptive but a bit cumbersome. The latter is admirably concise, but perhaps too unfamiliar. We note that the institutional features of the political system that give a party's leaders the ability to induce compliant behavior at a point in time are likely also the ones that allow a party to encourage its members to deliver on prior campaign promises. 
In this paper we do not model the instruments of party discipline explicitly, nor do we allow a party to choose how much discipline it wishes to impose. Rather, we treat party discipline in reduced form by parameterizing the costs that the party can impose on its politicians for failing to deliver on its promises. In this way, we are able to allow for continuous variation in the degree of party discipline and do more than just compare extreme differences in political regime. ${ }^{2}$

The organization and main findings of the paper are as follows. In the next section we highlight our core argument. We abstract from electoral competition and optimizing behavior by parties, and simply assume that the legislator from each geographic district is a member of either of two political parties with equal probability. When the legislature operates by majority rule and neglects minority interests, the expected tariff is always nonnegative and is positive when outputs respond positively to price and districts differ in their capital ownership. We argue that the protectionist bias reflects the convexity of the profit function and the lack of policy precommitment.

In Section III we develop our more complete model of the electoral-cum-policy-making process. The model includes three stages of policy announcement, district voting, and legislative deliberations. We solve for a subgame perfect equilibrium and show, in Section IV that a protectionist bias arises in both the rhetoric and reality of trade policy. Specifically, each party announces a vector of nonnegative tariffs (or export subsidies) as its platform and the random electoral process gives rise to a nonnegative average tariff. Both the announced positions and the expected tariffs are strictly positive when party discipline is less than perfect, output responds positively to price, and districts are not identical in their capital ownership.

In Section V we discuss economic and political determinants of the size of the bias. We show that both tariff announcements and expected tariffs are declining in a parameter that reflects the

2. McGillivray and Smith [1997] have studied trade policy formation in a plurality system with either high or low party discipline. They treat trade policy as a dichotomous variable (either "protectionist" or "free trade") and specify a different election-cum-policy game form depending on the degree of party discipline. Their main conclusion is that industries with broad geographic reach fare better in a system with low party discipline, while those concentrated in marginal districts fare better in a system with high party discipline. (See also McGillivray $[1997,2004]$.) While their paper shares some related concerns, their model and focus is quite different from ours. 
extent of party discipline but increasing in the disparity in ownership shares of any two districts, given the ownership share of the third. We also discuss the relationship between protection and the responsiveness of supplies and demands to price. Section VI concludes.

\section{The Core Argument}

In this section we explain how majoritarian politics can give rise to a protectionist bias in the trade policies of a small, open economy. We seek to lay bare the core of the argument in its simplest form. To this end, we abstract from electoral competition and the optimizing behavior of political parties. We focus instead on the policy choices of a legislature of exogenous (and random) composition, with legislators representing districts with disparate interests. Once the core argument is clear, it will be easier to understand the properties of our complete model, which captures complex interactions between parties, voters, and elected representatives.

Consider a small country populated by a unit measure of citizens that has one-third of the population living in each of three geographically distinct districts. Individuals consume four goods, labeled $1,2,3$, and $y$. Each individual has quasi-linear utility $c_{y}+\sum_{g=1}^{3} u\left(c_{g}\right)$, where $c_{y}$ is consumption of good $y$ and $u(\cdot)$ is an increasing and concave function of consumption $c_{g}$ of good $g$, $g \in\{1,2,3\}$. Assuming that every individual consumes some positive amount of good $y$, we write the indirect utility for individual $i$ residing in district $j$ as

$$
V_{i j}=I_{i j}+\sum_{g=1}^{3} S\left(p_{g}\right),
$$

where $I_{i j}$ is the individual's income net of lump-sum taxes and transfers, $S\left(p_{g}\right)$ is consumer surplus from consumption of good $g$, and $p_{g}$ is the domestic price of that good. The price $p_{g}$ of good $g$ is the sum of the given international price $p^{*}$ (the same for goods 1 , 2 , and 3 ) and the specific import tariff or export subsidy $t_{g}$, where $t_{g}<0$ represents an import subsidy or export tax. Note that $-S^{\prime}\left(p_{g}\right)=c\left(p_{g}\right)$ is the demand for good $g$, as usual.

The numeraire good $y$ is produced with one unit of labor per unit of output. We assume that the country produces a strictly 
positive quantity of this good in equilibrium, which fixes the wage rate at one. ${ }^{3}$ Each good $g \in\{1,2,3\}$ is produced with labor and an industry-specific factor that we call "capital." The return to each type of capital is an increasing and (weakly) convex function $\Pi\left(p_{g}\right)$ of the domestic price. The slopes of the profit functions give the competitive supply functions, $x_{g}=x\left(p_{g}\right)$.

We wish to make the districts symmetric both economically and politically, so as not to bias the political process in favor of any one district or group of citizens. To this end, we assume that the districts are symmetric in their ownership shares of capital, in the sense that residents of each district own a large share of the capital in one industry, a medium share in a second industry, and a small share in a third industry. In particular, let $\alpha_{1}, \alpha_{2}$, and $\alpha_{3}$ be three fractions with the property that $\alpha_{1} \geq \alpha_{2} \geq \alpha_{3} \geq 0$ and $\sum_{j=1}^{3} \alpha_{j}=1$. Let $\alpha_{j g}$ be the fraction of the capital in industry $g$ owned by residents of district $j$. Then, we impose symmetry by assuming that $\alpha_{11}=\alpha_{22}=\alpha_{33}=\alpha_{1}, \alpha_{21}=\alpha_{32}=\alpha_{13}=\alpha_{2}$, and $\alpha_{31}=\alpha_{12}=\alpha_{23}=\alpha_{3}{ }^{4}$

With this ownership structure, the aggregate income of district $j$ is

$$
I_{j}=\frac{1}{3}+\sum_{g=1}^{3} \alpha_{j g} \Pi\left(p_{g}\right)+\frac{1}{3} \sum_{g=1}^{3} t_{g} m\left(p_{g}\right),
$$

where $m\left(p_{g}\right)=c\left(p_{g}\right)-x\left(p_{g}\right)$ is imports (possibly negative) of good $g$, and thus the three terms in (2) represent labor income, capital income, and rebated tariff revenue, respectively. It follows from (1) and (2) that the aggregate welfare of residents of district $j$ is

$$
V_{j}=\frac{1}{3}+\sum_{g=1}^{3} \alpha_{j g} \Pi\left(p_{g}\right)+\frac{1}{3} \sum_{g=1}^{3}\left[S\left(p_{g}\right)+t_{g} m\left(p_{g}\right)\right] .
$$

3. Positive production of good $y$ requires a sufficiently large labor supply relative to the derived demand for labor by producers of goods 1,2 , and 3 at the prevailing equilibrium prices.

4. Once we impose symmetry in the distributions of ownership shares, we can label the districts and goods so that these assignments of shares are without further loss of generality. That is, we first pick any district and call it district 1 . Then we find the good for which district 1 has the largest share of capital and call that good 1. Next we identify the district that has the second largest share of capital in industry 1 and call that district 2 . We find the good for which district 2 has the largest share and label that good 2. Finally, we designate the remaining district as district 3 and the remaining good as good 3 . 
Suppose that each district is represented by a single legislator, who might be a member of either party $A$ or party $B$. For now, we do not specify how these legislators were elected, nor do we ascribe any trade policy positions to either political party. Rather, we simply assume a probability of one-half that the representative of district $j$ is a member of party $K$ for $j \in\{1,2,3\}$ and $K \in$ $\{A, B\}$, with independence across districts. Members of the same party can compensate one another with political side payments or intertemporal trades, so that any delegation from a given party will seek to maximize the representatives' joint welfare. In contrast, members of different parties have no reliable means to effect transfers, so that a legislator in the minority delegation cannot influence the policy decision. ${ }^{5}$ This captures in extreme the tyranny of the majority. Finally, suppose that each legislator represents the economic interests of her average constituent. ${ }^{6}$

The delegation of the majority party may have either two or three members. If the legislators in all three districts happen to be members of the same political party-which happens with probability one-quarter-they will select the vector of trade policies that maximizes $V_{1}+V_{2}+V_{3}$. Since this maximand is aggregate welfare and the country is small, they will opt for free trade in this situation. We record this observation as

$$
\mathbf{t}_{\{1,2,3\}}=0,
$$

where $\mathbf{t}_{L}$ denotes the policy vector enacted by a delegation that includes representatives of the set of districts $L$, where $\mathbf{t}_{L}=$ $\left(t_{L, 1}, t_{L, 2}, t_{L, 3}\right)$ and $t_{L, g}$ is the tariff applied to good $g$.

Next suppose that the representatives of districts $j$ and $k$ are members of one political party while the representative of district $l$ is a member of the other. For every combination of $j, k$, and $l$ (no two the same), this happens with probability one-quarter. In the

5. Dixit, Grossman, and Gul [2000] show how political compromise can arise from tacit cooperation in an infinitely repeated policy game even if the transfers across parties are impossible at a point in time. We do not consider the possibility of such cooperation here, relying for justification perhaps on the finite political lives of the legislators.

6. Willmann [2004] shows that voters in heterogeneous districts may have incentives to nominate and elect delegates to a national legislature who represent the interests of those who own more than the district average amount of sectorspecific capital. Such strategic delegation to extremists can benefit the district in legislative deliberations. The protectionist bias that we identify does not require that legislators are more extreme than their constituents and it would only be strengthened if this were the case. 
event, the majority delegation chooses the trade policy to maximize $V_{j}+V_{k}$, or

$$
\begin{aligned}
\mathbf{t}_{\{j, k\}}=\arg \max _{\mathbf{t}} \frac{2}{3}+\sum_{g=1}^{3}\left(\alpha_{j g}\right. & \left.+\alpha_{k g}\right) \Pi\left(p^{*}+t_{g}\right) \\
& +\frac{2}{3} \sum_{g=1}^{3}\left[S\left(p^{*}+t_{g}\right)+t_{g} m\left(p^{*}+t_{g}\right)\right] .
\end{aligned}
$$

The first-order conditions for this problem are

$$
\begin{aligned}
\left(\alpha_{j g}+\alpha_{k g}-2 / 3\right) x\left(p^{*}+t_{\{j, k\}, g}\right) & \\
& =-2 / 3 t_{\{j, k\}, g} m^{\prime}\left(p^{*}+t_{\{j, k\}, g}\right) \quad \text { for all } g .
\end{aligned}
$$

That is, the marginal benefit of a trade tax on good $g$ to residents of districts $j$ and $k$ matches its marginal cost. The marginal benefit is proportional to the districts' joint output of good $g$, and is positive or negative according to whether the residents of districts $j$ and $k$ together own more or less than the average national per capita share of the capital in the industry. The marginal cost reflects the familiar deadweight loss from protection.

To make the arguments more transparent, we henceforth adopt linear forms for the supply and demand functions, so that

$$
x\left(p_{g}\right)=x^{*}+\gamma\left(p_{g}-p^{*}\right)
$$

and

$$
c\left(p_{g}\right)=c^{*}-\beta\left(p_{g}-p^{*}\right),
$$

where $x^{*}$ and $c^{*}$ are, respectively, the quantities of each good produced and consumed at free-trade prices, and $\beta$ and $\gamma$ are nonnegative parameters. Then the representatives of districts $j$ and $k$ set the trade policy ${ }^{7}$

$$
t_{\{j, k\}, g}=\frac{\left(1 / 3-\alpha_{l g}\right) x^{*}}{(2 / 3)(\beta+\gamma)-\gamma\left(1 / 3-\alpha_{l g}\right)} \quad \text { for all } g, l \notin\{j, k\},
$$

where $l$ is the district excluded from the majority delegation. We maximizing $V_{j}+V_{k}$ always is satisfied. 
see from (7) that the majority provides positive protection for industry $g$ if and only if the residents of districts $j$ and $k$ together own more than two-thirds of the nation's capital in this industry (i.e., if the excluded district $l$ owns less than one-third of the capital). Otherwise, the majority sets a negative tariff or export subsidy for industry $g$.

When the three districts do not own exactly equal shares of all types of capital (i.e., when $\alpha_{l} \neq 1 / 3$ for some $l$ ), a majority of any two legislators sets at least one tariff that is positive and at least one tariff that is negative. The question we now ask is whether the average rate of protection is positive or negative when the majority delegation includes the representatives of districts $j$ and $k$ but not $l$. Equation (7) implies that the average tariff is ${ }^{8}$

$$
\bar{t}_{\{j, k\}}=\frac{1}{3} \sum_{l=1}^{3} \frac{\left(1 / 3-\alpha_{l}\right) x^{*}}{(2 / 3)(\beta+\gamma)-\gamma\left(1 / 3-\alpha_{l}\right)} .
$$

Note that the average does not depend on which two districts are included in the majority; this is a direct consequence of our assumption of symmetric ownership shares. Moreover, equation (8) implies that $\bar{t}_{\{j, k\}} \geq 0$ and $\bar{t}_{\{j, k\}}>0$ whenever $\gamma \neq 0$ and $\alpha_{l} \neq$ $1 / 3$ for some $l .{ }^{9}$ We also observe that the expected rate of protection is nonnegative in every industry (and positive whenever $\gamma \neq$ 0 and $\alpha_{l} \neq 1 / 3$ for some $l$ ), where the expectation is formed prior to the election and thus reflects an equal probability of each possible legislative majority. The expected protection for industry $g$ is $E\left[t_{L, g}\right]=3 \bar{t}_{\{j, k\}} / 4$, because a majority delegation with three members that chooses $t_{\{1,2,3\}, g}=0$ arises with probability $1 / 4$, while a delegation with two members that chooses $t_{\{j, k\}, g}$ also

8. Recall that $\alpha_{1}=\alpha_{11}=\alpha_{22}=\alpha_{33}, a_{2}=\alpha_{21}=\alpha_{32}=\alpha_{13}$, and $a_{3}=\alpha_{31}=$ $\alpha_{12}=\alpha_{23}$.

9. Note that

$\frac{\left(1 / 3-\alpha_{l}\right) x^{*}}{(2 / 3)(\beta+\gamma)-\gamma\left(1 / 3-\alpha_{l}\right)} \geq \frac{\left(1 / 3-\alpha_{l}\right) x^{*}}{(2 / 3)(\beta+\gamma)-\gamma(1 / 3-1 / 3)}=\frac{\left(1 / 3-\alpha_{l}\right) x^{*}}{(2 / 3)(\beta+\gamma)}$,

with strict inequality when $\gamma>0$ and $\alpha_{l}>1 / 3$ or $\alpha_{l}<1 / 3$. Therefore,

$$
\bar{t}_{\{j, k\}} \geq \sum_{l=1}^{3} \frac{\left(1 / 3-\alpha_{l}\right) x^{*}}{(2 / 3)(\beta+\gamma)}=0,
$$

and the inequality is strict if $\gamma>0$ and $\alpha_{l} \neq 1 / 3$ for some $l$. 
arises with probability $1 / 4$, for each of the three possible combinations of $j$ and $k$.

Why the bias in the average protection? Clearly, it derives from the convexity of the profit function, as well as features of the assumed policy-making process. The convexity of profits implies that the marginal benefit of protection increases with $t_{g}$ when $t_{g}$ is positive, but decreases with minus $t_{g}$ when $t_{g}$ is negative. As a consequence, the positive tariffs that emerge when the majority favors protection are larger on average than the import subsidies that emerge when the opposite is true. The key assumptions about policy-making that are needed for the result are that (i) candidates and parties cannot fully commit to policies prior to the election and (ii) legislators in the minority delegation cannot fully compensate those in the majority to ensure that their constituents' interests receive equal weight. If prior commitment were possible, the candidates in each party would announce the vector $\mathbf{t}$ to maximize their constituents' expected welfare. The choice for each party would be free trade. And if the minority legislators could make lump-sum transfers to the majority in the ex post deliberations, again the welfare-maximizing choice would be free trade in all possible legislatures.

In the next section we develop a more complete model of the political process. The model includes political parties that choose platforms, voters who maximize expected utility, and legislators who set policy. A parameter of the model represents the extent to which the parties can bind the ex post behavior of their geographically minded politicians. We shall find that a protectionist bias exists whenever party discipline is less than perfect. We will then be in a position to investigate the determinants of the size of the protectionist bias.

\section{Platforms, Elections, and Legislative Action}

We study a majoritarian system with three geographic districts, two political parties, and a continuum of voters. The districts are distinguished by their capital ownership shares. The parties are distinguished by their ideologies and other exogenous characteristics. Voters differ in their ideological preferences and in their capital ownership.

The political game has three stages. In the first stage, the parties choose platforms $\tau^{A}$ and $\tau^{B}$, which they announce to the electorate. $\tau^{K}=\left(\tau_{1}^{K}, \tau_{2}^{K}, \tau_{2}^{K}\right)$ is a vector, with $\tau_{g}^{K}$ representing the 
announced rate of protection in sector $g$. As before, $\tau_{g}^{K}>0$ represents a (specific) import tax or export subsidy, while $\tau_{g}^{K}<0$ represents an import subsidy or export tax. We assume that the party cares most about its ideological agenda, which it will be able to implement if and only if it captures a majority of the seats in the legislature. The party might also weigh the expected political welfare of its political candidates. Then its objective function would include a component to reflect the candidates' expected utility not only from the ideological outcomes, but also from their more parochial concerns. But, to highlight the divergence between ex ante and ex post objectives that generate the party's commitment problem, we adopt an extreme formulation in which the national party puts negligible weight on the ex post benefits and costs to the individual legislators. Accordingly, we take the party's objective as being to maximize the probability of an electoral victory.

Next come the district elections. Each district elects a single representative to the three-member legislature. The heterogeneous citizens in a district care about trade policy and about other (fixed) characteristics of the party that is elected. An individual in district $j$ votes for the candidate from party $A$ if and only if, given the probability distribution of electoral outcomes in districts $k$ and $l$, his expected utility is higher when the candidate from this party wins in district $j$ than when the candidate from party $B$ wins in his district.

Finally, the legislature sets policy. Of course, the majority delegation enacts the set of ideological policies that its party prefers. We assume that these legislators choose their trade policy to maximize aggregate welfare of residents of the districts they represent net of any penalties they will suffer by deviating from their party's platform. The maximization of constituents' welfare can be justified on the basis that this generates private political benefits for the politicians, or because these are "citizencandidates" (as in Besley and Coate [1997] or Osborne and Slivinski [1996]) who share the trade policy preferences of their fellow district residents. We discuss the penalties further below.

We seek a subgame perfect equilibrium of the three-stage political game. In such an equilibrium, the voters correctly anticipate the influence that the platform announcements will have on the policies that emerge from the legislature and the parties correctly anticipate how their announcements will affect voting behavior. As usual, we solve the game "backwards," by first con- 
sidering the legislative deliberations, then the voting, and finally the platform choices.

\section{III.A. Policy Formation}

By the time the legislature convenes to set trade policy, the parties will have announced platforms $\tau^{A}$ and $\tau^{B}$, and the voters will have elected some party $K$ to a majority position comprising the set of districts $L$. We assume that the majority delegation sets the trade policy vector, which we denote by $\mathbf{t}_{L}^{K}$, to maximize the aggregate welfare of residents of the districts in $L$ net of any penalty they suffer for deviating from their party's announcement $\tau^{K}$. We discuss each component in turn.

Citizen $i$ in district $j$ realizes utility

$$
W_{i j}^{K}=V_{i j}\left(\mathbf{t}_{L}^{K}\right)+\mu_{i j}^{K}+v_{j}^{K}
$$

when party $K$ wins a majority comprising the set of districts $L$ and sets the trade policy $\mathbf{t}_{L}^{K}$. In (9), $V_{i j}$ is a utility component from the economic policy that derives from the quasi-linear preferences given in (1), while $\mu_{i j}^{K}$ and $v_{j}^{K}$ are components that derive from the individual's evaluation of the ideological positions and other characteristics of political party $K$ (the former idiosyncratic, the latter common to all residents of district $j$ ). The production technologies are the same as before; i.e., good $y$ is produced with labor alone, while good $g$ is produced with labor and capital, for $g=1,2,3$. We assume for expositional simplicity that every resident of district $j$ owns the same amount of capital. ${ }^{10}$ Then

$$
\begin{aligned}
V_{i j}\left(\mathbf{t}_{L}^{K}\right)=3 V_{j}\left(\mathbf{t}_{L}^{K}\right)=1+ & 3 \sum_{g=1}^{3} \alpha_{j g} \Pi\left(p^{*}+t_{L, g}^{K}\right) \\
& +\sum_{g=1}^{3}\left[S\left(p^{*}+t_{L, g}^{K}\right)+t_{L, g}^{K} m\left(p^{*}+t_{L, g}^{K}\right)\right],
\end{aligned}
$$

where $3 \alpha_{j g}$ is the per capita ownership share in district $j$ of the capital of industry $g$. Again, we assume that ownership shares are symmetric across districts, so that each district owns a fraction $\alpha_{1}$ of the capital in one industry, a fraction $\alpha_{2}$ of the capital in another, and a fraction $\alpha_{3}$ of the capital in a third.

10. Our results would be exactly the same if residents of a district were heterogeneous in their capital endowments provided that the distribution of ownership shares were independent of the distribution of ideological preferences. 
The penalty for deviating from $\tau^{K}$ represents the national party's ability and willingness to enforce "party discipline." We assume that party $K$ levies a "fine" of $(1 / 2) \delta \sum_{g=1}^{3}\left(t_{L, g}^{K}-\tau_{g}^{K}\right)^{2}$ in units of political welfare when a majority delegation from party $K$ chooses the policy $\mathbf{t}_{L}^{K}$ instead of the party's previously announced platform, $\tau^{K}$. The fine is borne by the elected legislators from party $K$ and represents a counterweight to their goal of serving their local constituents. We do not model the instruments that the party uses to impose the penalty, nor can we capture in our static model the reasons why the party carries out the punishment ex post. Rather, we take $\delta$ as a reduced-form measure of the institutional environment. ${ }^{11}$ If, for example, $\delta=0$, the legislative majority can set the trade policy with complete impunity, as in the citizen-candidate models of Besley and Coate [1997] and Osborne and Slivinski [1996]. At the opposite extreme, if $\delta \rightarrow \infty$, the legislators cannot afford to deviate at all from the party's announcement, as in Downsian models with policy commitment.

Aggregate welfare of the residents of districts $L$ is given by the sum of $\sum_{j \in L} V_{j}\left(\mathbf{t}_{L}^{K}\right)$ and terms that are independent of $\mathbf{t}_{L}^{K}$. Therefore,

$$
\begin{aligned}
& \mathbf{t}_{L}^{K}=\underset{\mathbf{t}}{\arg \max _{j \in L}} \sum_{j=1}\left\{\frac{1}{3}+\sum_{g=1}^{3} \alpha_{j g} \Pi\left(p^{*}+t_{L, g}^{K}\right)\right. \\
& \left.+\frac{1}{3} \sum_{g=1}^{3}\left[S\left(p^{*}+t_{L, g}^{K}\right)+t_{L, g}^{K} m\left(p^{*}+t_{L, g}^{K}\right)\right]\right\}-\frac{1}{2} \delta \sum_{g=1}^{3}\left(t_{L, g}^{K}-\tau_{g}^{K}\right)^{2},
\end{aligned}
$$

which, with the linear supply and demand functions (5) and (6), implies that the tariffs are

$$
t_{\{1,2,3\}, g}^{K}=\frac{\delta \tau_{g}^{K}}{\beta+\gamma+\delta}
$$

when party $K$ captures all three seats in the legislature, and

11. We imagine, for example, that $\delta$ will be larger the greater is the national party's control over campaign finances in regional elections. Similarly, $\delta$ might be large if the national party exercises firm control over the allocation of committee posts and patronage positions. See Snyder and Groseclose [2000] and McCarty, Pool, and Rosenthal [2001] for attempts to measure how party discipline in the U. S. Congress has varied over time. Note, however, that these authors define party discipline somewhat differently than we do. Whereas we define discipline as adherence to previously announced positions of the national parties, they examine whether "backbenchers" in the legislature vote as a block with legislative party leaders. Clearly, these two manifestations of discipline are related but not the same. 


$$
t_{\{j, k\}, g}^{K}=\frac{\left(1 / 3-\alpha_{l g}\right) x^{*}+\delta \tau_{g}^{K}}{(2 / 3)(\beta+\gamma)+\delta-\gamma\left(1 / 3-\alpha_{l g}\right)}
$$

when party $K$ captures seats in districts $j$ and $k$ but not in $l .{ }^{12}$

From (11) we see that a majority delegation comprising representatives of all three districts does not choose free trade unless either the party's platform is one of free trade or $\delta=0$. Although free trade maximizes aggregate welfare, the legislators may choose a different trade policy to temper the response by their national party. In fact, since the aggregate welfare cost of a small deviation from free trade is small, a legislature of the whole will always move some way in the direction of the party's platform unless discipline is totally absent.

When the majority party holds seats in only two districts, the resulting policy reflects both the capital holdings of the citizens in these districts and the prior party announcement. The majority delegation sets a positive tariff on imports of good $g$ whenever their party has advocated protection and the residents of the districts in the majority together own at least two-thirds of the capital in that industry. The tariff $t_{\{j, k\}, g}^{K}$ may be positive even when $\alpha_{j g}+\alpha_{k g}<2 / 3$ if party $K$ 's platform calls for protection of industry $g$ and party discipline is sufficiently strong.

\section{III.B. The Elections}

We turn to the second stage, when the voters cast their ballots in anticipation of the policy choices that will result from the different possible legislatures. A voter in district $j$ cannot perfectly predict the election outcomes in districts $k$ and $l$. He votes for the candidate who offers him the higher expected utility in the light of this uncertainty.

Voters are heterogeneous in their political preferences. In district $j, \mu_{i j}^{K}$ represents the idiosyncratic component of voter $i$ 's evaluation of the fixed characteristics of party $K$, while $\nu_{j}^{K}$

12. Since the domestic price $p^{*}+t_{L, g}^{K}$ cannot be negative and per capita consumption $c^{*}-\beta t_{L, g}^{K}$ cannot be negative, there are lower and upper bounds on the permissible tariffs; namely,

$$
-p^{*} \leq t_{L, g}^{K} \leq c^{*} / \beta .
$$

Also, output of good $y$ has been assumed to be positive, which places a further restriction on the maximum size of $\mathbf{t}_{L}^{K}$. Our formulas apply as long as the resulting tariff levels are within the relevant bounds. 
represents a district-specific component. Let $\mu_{i j}=\mu_{i j}^{B}-\mu_{i j}^{A}$, and $v_{j}=v_{j}^{B}-v_{j}^{A}$. We assume that, in every district $j, \mu_{i j}$ is distributed uniformly on $[-1 / 2 h, 1 / 2 h]$. This means that the average (and median) voter in each district has no political leanings toward one party or the other, given the values of the district shocks and apart from the voter's assessment of any differences in their trade platforms. The inverse of the parameter $h$ measures the diversity of political opinions within a district. The random variable $v_{j}$ is a popularity or "valence" shock that affects the relative evaluations of the two parties similarly for all residents of district $j$. Each resident knows the value of $v_{j}$ by the time he enters the voting booth, but not the values of $v_{k}$ and $v_{l}$. The popularity shocks are distributed independently across districts; each has a cumulative distribution function $F(v)$, with $F(0)=1 / 2$ and a density function that is positive at $v=0$ and symmetric about this point. Thus, the mean popularity shock favors neither political party.

Voter $i$ in district $j$ evaluates his expected utility conditional on a local victory by each candidate, recognizing his uncertainty about the election outcome in the other two districts. For example, if the candidate from party $A$ wins in district 1 , equations (9) and (10) imply that the expected utility for voter $i$ is

$$
\begin{aligned}
& E\left[W_{i 1}^{A}\right]=\rho_{2} \rho_{3}\left[3 V_{1}\left(\mathbf{t}_{\{1,2,3\}}^{A}\right)+\mu_{i 1}^{A}+v_{1}^{A}\right] \\
& +\rho_{2}\left(1-\rho_{3}\right)\left[3 V_{1}\left(\mathbf{t}_{\{1,2\}}^{A}\right)+\mu_{i 1}^{A}+\nu_{1}^{A}\right]+\rho_{3}\left(1-\rho_{2}\right)\left[3 V_{1}\left(\mathbf{t}_{\{1,3\}}^{A}\right)\right. \\
& \left.\quad+\mu_{i 1}^{A}+v_{1}^{A}\right]+\left(1-\rho_{2}\right)\left(1-\rho_{3}\right)\left[3 V_{1}\left(\mathbf{t}_{\{2,3\}}^{B}\right)+\mu_{i 1}^{B}+v_{1}^{B}\right],
\end{aligned}
$$

where $\rho_{j}$ is the voter's assessment of the probability that party $A$ will win in district $j$ for $j \neq 1$. The first term on the right-hand side gives the product of the voter's utility if party $A$ also wins in districts 2 and 3 and the voter's assessment of the likelihood of that event. Notice that a victory by party $A$ in all three districts foretells a tariff vector $\mathbf{t}_{\{1,2,3\}}^{A}$ and political utility components $\mu_{i 1}^{A}$ and $v_{1}^{A}$ for voter $i$. The other terms have similar interpretations; note in particular the last term, which gives the voter's assessment of the probability that party $A$ will be defeated in districts 2 and 3 , in which case the majority coalition from party $B$ will set the tariff vector $\mathbf{t}_{\{2,3\}}^{B}$ and the voter will experience the political utility components associated with that political party.

We can write an analogous expression for $E\left[W_{i 1}^{B}\right]$ and then compute the difference, $E\left[W_{i 1}^{A}\right]-E\left[W_{i 1}^{B}\right]$. The voter $i$ in district 1 casts his ballot for the candidate from party $A$ if and only if this 
difference is positive. More generally, the voter $i$ in district $j$ votes for the candidate from party $A$ if and only if

$$
\mu_{i j}<\Delta_{j} / \theta_{j}-v_{j}
$$

where

$$
\begin{aligned}
\Delta_{j}= & \rho_{k} \rho_{l}\left[3 V_{j}\left(\mathbf{t}_{\{1,2,3\}}^{A}\right)-3 V_{j}\left(\mathbf{t}_{\{k, l\}}^{A}\right)\right] \\
& +\rho_{k}\left(1-\rho_{l}\right)\left[3 V_{j}\left(\mathbf{t}_{\{j, k\}}^{A}\right)-3 V_{j}\left(\mathbf{t}_{\{j, l\}}^{B}\right)\right]+\rho_{l}\left(1-\rho_{k}\right) \\
& \times\left[3 V_{j}\left(\mathbf{t}_{\{j, l\}}^{A}\right)-3 V_{j}\left(\mathbf{t}_{\{j, k\}}^{B}\right)\right]+\left(1-\rho_{k}\right)\left(1-\rho_{l}\right) \\
& \times\left[3 V_{j}\left(\mathbf{t}_{\{k, l\}}^{B}\right)-3 V_{j}\left(\mathbf{t}_{\{1,2,3\}}^{B}\right)\right]
\end{aligned}
$$

and $\theta_{j}=\rho_{k}\left(1-\rho_{l}\right)+\rho_{l}\left(1-\rho_{k}\right)$ is the probability that district $j$ will prove to be pivotal in the legislative election.

Considering the uniform distribution of $\mu_{i j}$, the fraction of votes that party $A$ will capture in district $j$ (as a function of $v_{j}$ ) is given by $s_{j}=1 / 2+h\left(\Delta_{j} / \theta_{j}-v_{j}\right)$ and the probability that $s_{j}>$ $1 / 2$ is the probability that $v_{j}<\Delta_{j} / \theta_{j}$. But $v_{j}$ has the cumulative distribution $F(\cdot)$. It follows that the probability that party $A$ will capture the seat in district $j$ (as viewed by outsiders) is given by

$$
\rho_{j}=F\left[\frac{\Delta_{j}}{\rho_{k}\left(1-\rho_{l}\right)+\rho_{l}\left(1-\rho_{k}\right)}\right] .
$$

Equations (10)-(14) can be used to solve for the probabilities $\rho_{1}$, $\rho_{2}$, and $\rho_{3}$ as functions of the announced platforms, $\tau^{A}$ and $\tau^{B}{ }^{13}$

\section{III.C. The Campaign}

We turn to the first stage, when the parties announce their tariff platforms. At this stage, they do not know the values of the popularity shocks. The leaders of each party choose their platform to maximize the probability that they will capture a majority of the seats in the legislature. Party $A$ wins a majority if it wins in any two districts or in all three. The probability of a victory by party $A$ thus equals

13. The equations (10)-(14) always have a solution with $\rho_{1}=\rho_{2}=\rho_{3}=0$ and one with $\rho_{1}=\rho_{2}=\rho_{3}=1$. If a voter in district $j$ expects either party to win with certainty in the other two districts, it is a dominant strategy for him to vote for this same party irrespective of the parties' tariff platforms and his own political leanings. This is because the election in his own district cannot affect the determination of the majority party, but only whether district $j$ will be included or excluded from the policy-making process. In the equilibria we have just described, every citizen in the country votes for the same party. Such equilibria arise only with extreme coordination of expections. For this reason, we do not consider them any further. 


$$
\rho=\rho_{1} \rho_{2}\left(1-\rho_{3}\right)+\rho_{1}\left(1-\rho_{2}\right) \rho_{3}+\left(1-\rho_{1}\right) \rho_{2} \rho_{3}+\rho_{1} \rho_{2} \rho_{3} .
$$

The leaders of party $B$ aim to minimize $\rho$, or to maximize $1-\rho$. We seek a Nash equilibrium of this zero-sum game.

Recall that the voters' economic interests are independent of their party loyalties. Thus, the parties have similar incentives with regard to trade policy. Moreover, we have introduced no bias in the parties' ideological appeal ( $\mu_{i j}$ is symmetrically distributed with mean zero in every district) and no bias in the popularity shocks $\left(v_{j}\right.$ is symmetrically distributed with mean zero in every district). It is thus reasonable to look for an equilibrium in which the parties announce the same trade platforms $\left(\tau^{A}=\tau^{B}\right)$, offer the same economic welfare to a given district $\left(\Delta_{j}=0\right.$ for all $\left.j\right)$ and achieve the same probabilities of victory $\left(\rho_{j}=1 / 2\right.$ for all $\left.j\right)$. Furthermore, the industries look similar to the political parties prior to the elections. Therefore, it is reasonable to suppose that they announce a similar trade tax for each good; i.e., $\tau_{g}^{K}=\tau$ for $g=1,2,3$. We henceforth focus on symmetric equilibria with these properties.

Consider the choice of trade platform by party $A$. The firstorder condition for maximizing $\rho$ is given by

$$
\frac{\partial \rho}{\partial \tau_{g}^{A}}=\sum_{j=1}^{3}\left[\rho_{k}\left(1-\rho_{l}\right)+\rho_{l}\left(1-\rho_{k}\right)\right] \frac{\partial \rho_{j}}{\partial \tau_{g}^{A}}=0 \quad \text { for all } g .
$$

With $\rho_{k}=\rho_{l}=1 / 2$ at a symmetric equilibrium, this simplifies to

$$
\sum_{g=1}^{3} \frac{\partial \rho_{j}}{\partial \tau_{g}^{A}}=0 \quad \text { for all } g .
$$

We next use the system of equations (10)-(14) to calculate the partial derivatives in (15). In the appendix we show that (15) is satisfied for good $g$ if and only if ${ }^{14}$

$$
\begin{aligned}
\sum_{l=1}^{3}\left[2\left(\frac{1}{3}-\alpha_{l g}\right)\left(x^{*}+\gamma t_{\{-l, g}^{A}\right)-\frac{1}{3} t_{\{-l\}, g}^{A}(\beta+\gamma)\right] \frac{\partial t_{\{-l, g}^{A}}{\partial \tau_{g}^{A}} & \\
& -t_{\{1,2,3\}}^{A}(\beta+\gamma) \frac{\partial t_{\{1,2,3\}}^{A}}{\partial \tau_{g}^{A}}=0,
\end{aligned}
$$

14. This requires a restriction on $F^{\prime}(0)$, which we discuss in the appendix. 
where $t_{\{-l\}, g}^{A}$ is the tariff on good $g$ that will be set by a majority delegation that includes representatives of districts $j$ and $k$ but not $l$. When the solutions for the realized tariff rates are finite and such that the output of good $y$ and consumption of good $g$ are positive, we can use equations (11) and (12) to calculate the responses of these tariffs to changes in the party's announcement.

To simplify the exposition, we place a restriction on the parameter values. We adopt ${ }^{15}$

Assumption 1. $\frac{\beta+\gamma}{(\beta+\gamma)^{2}}+\sum_{l=1}^{3} \frac{(1 / 3)(\beta+\gamma)-2 \gamma\left(1 / 3-\alpha_{l}\right)}{\left[(2 / 3) \beta+(2 / 3) \gamma-\gamma\left(1 / 3-\alpha_{l}\right)\right]^{2}}>0$.

Then the first-order condition pins down a unique value of $\tau_{g}^{A}$, which is also the equilibrium value of $\tau_{g}^{B}$. In a symmetric Nash equilibrium, the parties announce $\tau^{A}$ and $\tau^{B}$ such that $\tau^{A}=\tau^{B}=$ $(\tau, \tau, \tau)$ and

$$
\begin{aligned}
\tau= & (\beta+\gamma+2 \delta) x^{*} \sum_{l=1}^{3} \frac{1 / 3-\alpha_{l}}{\left[(2 / 3) \beta+\delta+(2 / 3) \gamma-\left(1 / 3-\alpha_{l}\right) \gamma\right]^{2}} / \\
& \delta\left\{\frac{\beta+\gamma}{(\beta+\gamma+\delta)^{2}}+\sum_{l=1}^{3} \frac{(1 / 3)(\beta+\gamma)-2\left(1 / 3-\alpha_{l}\right) \gamma}{\left[(2 / 3) \beta+\delta+(2 / 3) \gamma-\left(1 / 3-\alpha_{l}\right) \gamma\right]^{2}}\right\} .
\end{aligned}
$$

This expression for $\tau$ gives the parties' common equilibrium tariff announcement as a function of the parameters of the model: $\left\{\alpha_{j}\right\}$, $\beta, \gamma$, and $\delta .{ }^{16}$ Then we can substitute $\tau$ into (11) and (12) to solve for the actual tariff rates for the various possible election results. In what follows, we assume that the parameter values obey Assumption 1 and that $F^{\prime}(0)$ is sufficiently small that the secondorder conditions are satisfied.

15. Assumption 1 ensures that the first-order condition has a finite solution for all positive values of $\delta$. Without this assumption, the solution to (17) would involve the announcement and enactment of an infinite tariff for some finite values of $\delta$, which would not be consistent with our assumption that demand is linear and the requirement that consumption is nonnegative.

16. We have not been able to examine the second-order conditions for a party's best response to its rival's equilibrium platform using analytical methods; the resulting expressions are too complex. Instead, we have computed a set of numerical examples and have examined the conditions under which the platform in (17) describes a best response to a similar announcement by the rival party. We find that Assumption 1 together with an assumption that $F^{\prime}(0)$ is sufficiently small ensure the existence of the symmetric equilibrium described by (17). When $F^{\prime}(0)$ is large, however, the second-order conditions for the best response by party $A$ to party $B$ 's platform are violated at (17). 


\section{Equilibrium Platforms and Policies}

In this section we use equations (11), (12), and (17) to characterize the equilibrium platforms and policies. In so doing, we establish a protectionist bias in both the rhetoric and reality of trade policy.

\section{IV.A. The Rhetoric of Trade Policy}

We focus first on the parties' announcements. We prove ${ }^{17}$

Proposition 1. Let $\tau=(\tau, \tau, \tau)$ be the equilibrium platform in a symmetric equilibrium. (i) For $\delta>0$, if $\gamma=0$ or $\alpha_{j}=1 / 3$ for all $j$, then $\tau=0$. Otherwise $\tau>0$. (ii) $\lim _{\delta \rightarrow \infty} \tau=0$.

Proposition 1 establishes the existence of a protectionist bias in the parties' platforms. The parties never promise import subsidies or export taxes. Moreover, they promise free trade only if the districts are homogeneous in their capital ownership shares (and thus their trade policy preferences) or if the supplies of the nonnumeraire goods are unresponsive to price. For all finite $\beta$ and $\delta$, if $\gamma$ is positive and finite, and not all ownership shares are the same, the parties announce positive import tariffs or export subsidies.

The conditions for a positive bias are the same as in Section II. A bias arises when the districts are heterogeneous, the profit functions are convex, and the parties are unable to precommit to policy. If $\alpha_{1}=\alpha_{2}=\alpha_{3}=1 / 3$, there is no scope for trade policy to redistribute income. In such circumstances, trade policies impose deadweight without offering any compensating benefits, and so voters in every district covet free trade. Then the parties have no reason to promise anything else. If $\gamma=0$, industry rents are linear in price. Then the marginal gains to those who benefit from increased protection when tariffs are positive are similar to the marginal gains to those who benefit from decreased protection when tariffs are negative. In the event, the parties find no reason to deviate from a free-trade rhetoric in one direction or the other. Finally, as $\delta$ approaches infinity, the announcements converge on free trade. A very high value of $\delta$ allows the parties virtually to commit to a trade policy. As in Lindbeck and Weibull [1987], the optimal commitment is to a policy that maximizes average welfare, which is free trade.

17. All proofs are in the appendix. 


\section{IV.B. The Reality of Trade Policy}

Next we examine the policies that emerge from different compositions of the legislature. When the majority party captures three seats, equation (11) implies that $t_{\{1,2,3\}, g}=\bar{t}_{\{1,2,3\}}$ for $g \in$ $\{1,2,3\}$ and that

$$
\bar{t}_{\{1,2,3\}}=\delta \tau /(\beta+\gamma+\delta),
$$

where $\tau$ is the equilibrium platform given in (17). When the majority wins the election in districts $j$ and $k$ but not $l$, the average tariff across the three industries is

$$
\bar{t}_{\{j, k\}}=\frac{1}{3}\left[\sum_{l=1}^{3} \frac{\left(1 / 3-\alpha_{l}\right) x^{*}+\delta \tau}{(2 / 3)(\beta+\gamma)+\delta-\gamma\left(1 / 3-\alpha_{l}\right)}\right],
$$

where $\tau$ again is the equilibrium platform given in (17). Note that the average $\bar{t}_{\{j, k\}}$ does not depend on which districts $j$ and $k$ are represented in the majority. We organize our discussion around

Proposition 2. (i) If $\alpha_{l}=1 / 3$ for all $l$, then $t_{L, g}=0$ for all $L$ and g. (ii) $\lim _{\delta \rightarrow \infty} t_{L, g}=0$ for all $L$ and $g$. (iii) For $\delta>0$, if $\gamma=0$ or $\alpha_{l}=1 / 3$ for all $l$, then $\bar{t}_{L}=0$ for all $L$, and $E\left[t_{L, g}\right]=0$ for all $g$. Otherwise $\bar{t}_{L}>0$ for all $L$, and $E\left[t_{L, g}\right]>0$ for all $g$.

Part (i) of Proposition 2 states that, when the districts are homogeneous in their capital ownership shares, free trade prevails in all industries no matter what the electoral outcome. This follows from the fact that each party announces a platform of free trade and no elected officials have any reason to depart from these promises. For example, when the legislature has two members in the majority delegation, the representatives will escape penalties by enacting free trade, and will also maximize the welfare of their constituents (which amounts to two-thirds of aggregate welfare). If all three legislators belong to the same party, again a policy of free trade avoids penalties and maximizes constituents' welfare.

Free trade also prevails in the limit as party discipline becomes perfect. As $\delta$ approaches infinity, the parties maximize their prospects of victory by appealing to the average voter (see Proposition 1 part (ii)). And once they have promised free trade, the elected representatives will find it too costly to stray from these announcements.

Now consider the trade policies that result when one party 
wins the election in all three districts and ownership shares are not all the same. Suppose that the supply curves for goods 1,2 , and 3 slope upward. The residents of the three districts comprise the entirety of the country, so free trade in every good would maximize their collective welfare. But, we know from Proposition 1 that their party leaders will have promised positive protection for every industry. As long as $\delta>0$, the legislators will sacrifice some goodwill among voters to appease their party leaders. Equation (11) tells us that $\tau>0$ implies $t_{\{1,2,3\}, g}>0$ for all finite and positive $\beta, \gamma$, and $\delta$.

What happens when the majority party wins in only two districts (say, 1 and 2) and ownership shares are not all the same? Consider the trade policy for industry 1 , in which residents of districts 1 and 2 collectively own more than two-thirds of the national capital stock. Then, even if $\gamma=0$ and the parties have announced free trade, the legislature will set a positive tariff; i.e., $t_{\{1,2\}, 1}>0$. Here, the penalty to the legislators for small departures from the announcement are small while the constituent gains from protection are large. And if $\gamma \neq 0$ so that $\tau>0$, both the dictates of party discipline and constituents' interests point to a positive tariff. The actual protection for industry 1 may exceed or fall short of the campaign promise, depending on the extent of party discipline. Indeed, we find that $t_{\{1,2\}, 1}<\tau$ if $\delta$ is sufficiently small, but $t_{\{1,2\}, 1}>\tau$ if $\delta$ is sufficiently large. ${ }^{18}$

Now consider the tariff on good 3. Recall that $\alpha_{13}+\alpha_{23}=$ $\alpha_{2}+\alpha_{3}<2 / 3$. Then $t_{\{1,2\}, 3}$ may be either positive or negative. Assuredly, an import subsidy (or export tax) for good 3 serves the interests of the represented citizens. But the majority party will have promised a positive tariff for this industry, just as for the others. The elected representatives must weigh the costs of disappointing their constituents against those of deviating from their party's position. It is not difficult to generate examples in which $t_{\{1,2\}, 3}>0$ even though the $\alpha_{13}+\alpha_{23}$ is small. It is even possible for $t_{\{1,2\}, 3}>0$ when $\alpha_{13}+\alpha_{23}=0$; i.e., when residents of the districts in the majority own no capital at all in industry

18. Using (12) and (17), it is easy to check that the sign of $t_{\{1,2\}, 1}-\tau$ is opposite to that of

$$
\tau-\frac{\left(1 / 3-\alpha_{3}\right) x^{*}}{(2 / 3)(\beta+\gamma)-\gamma\left(1 / 3-\alpha_{3}\right)} .
$$

But (17) implies that $\tau \rightarrow \infty$ as $\delta \rightarrow 0$ and $\tau \rightarrow 0$ as $\delta \rightarrow \infty$. Moreover, we show in the appendix that $\tau$ is declining in $\delta$. Together this establishes that $t_{\{1,2\}, 1}>\tau$ for $\delta$ large, and $t_{\{1,2\}, 1}<\tau$ for $\delta$ small. 
$3 .{ }^{19}$ In such circumstances, the protectionist bias in the announcement induces positive protection for all industries and all electoral outcomes.

But even in circumstances when protection for some industries can be negative, a protectionist bias remains. As part (iii) of Proposition 2 indicates, the average tariff can never be negative, and must be positive for any legislative majority so long as ownership shares are not all the same and supply curves slope upward. Also, the expected tariff on any good is positive under these circumstances, where the expectation is formed prior to the election. The protectionist bias in the average trade policy and the expected tariff for a given industry mirrors the bias in the equilibrium platform.

\section{The Size of the Bias}

In this section we examine the political and economic determinants of the parties' equilibrium platforms and the legislature's policy choices. We focus especially on party discipline and the geographic distribution of the capital stock, but also discuss briefly the slopes of the demand and supply functions.

As we have noted, the parameter $\delta$ in our model captures the degree of party discipline. It measures the cost to individual legislators of deviating from the policy advocated by party leaders. While our static model does not allow endogenous determination of the size of $\delta$, we imagine that it reflects institutional features of the political landscape, such as the party role in campaign financing and in the distribution of the perquisites of political office.

In the appendix we prove ${ }^{20}$

Proposition 3. Suppose that $\gamma>0$ and $\alpha_{l} \neq 1 / 3$ for some $l$. Then,

(i) For finite $\delta>0, \partial \tau / \partial \delta<0$, and $\partial E\left[t_{L, g}\right] / \partial \delta<0$ for all $g$.

(ii) $\lim _{\delta \rightarrow 0} \tau=\infty$ but $\lim _{\delta \rightarrow 0} t_{L, g}<\infty$ for all $L$ and $g$. (iii) $\lim _{\delta \rightarrow \infty} \tau=0$, and $\lim _{\delta \rightarrow \infty} t_{L, g}=0$ for all $L$ and $g$.

The proposition states that the protectionist bias declines monotonically with the severity of party discipline. When $\delta$ is very small, the political rhetoric is shrill. The party leaders have very

19. This happens, for example, when $\beta=1, \gamma=1$, and $\delta=1$. Then, if $\alpha_{2}=$ $\alpha_{3}=0, \tau=0.83$, and $t_{\{1,2\}, 3}=0.06$.

20. Part (iii) of this proposition is just a restatement of elements of Propositions 1 and 2 and is repeated here only for completeness. 


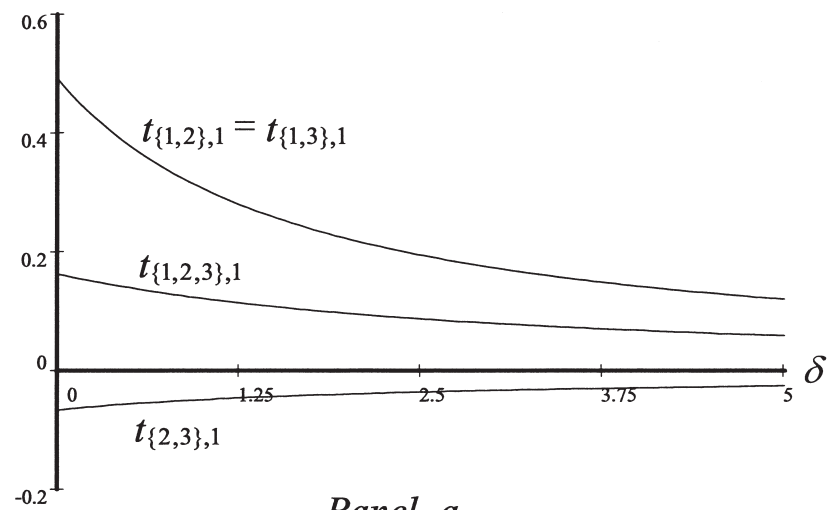

Panel a

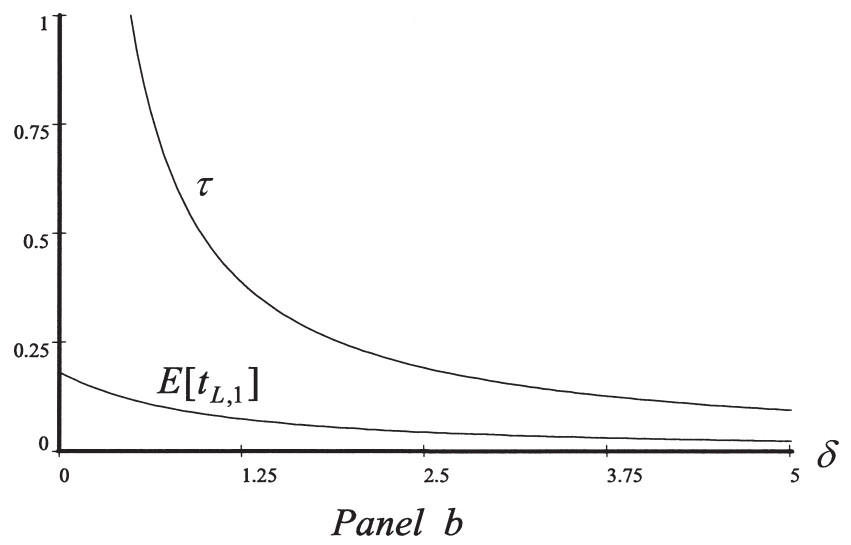

FIGURE I

Negative Protection for Some Industries

limited means to bind the ex post behavior of the elected representatives, so they attempt to do what they can by announcing extreme positions. But the announcements are largely ignored by the representatives who bear relatively little political cost from doing so. The actual tariffs remain finite even as the platforms tend to infinity. Still, the expected tariff on each good is higher as $\delta$ approaches zero than for any positive value of $\delta$.

In Figure I we show the relationship between the equilibrium platforms and policies and our measure of party discipline for one set of parameter values. In drawing the figure, we have assumed that, for each industry $g$, all capital is owned by residents of a single district (i.e., $\alpha_{1}=1 ; \alpha_{2}=\alpha_{3}=0$ ) and that $\beta=2, \gamma=1$, and 
$x^{*}=1$. The top panel in the figure shows that, for these parameter values, the tariff on good 1 is positive whenever district 1 is included in the majority delegation (i.e., $t_{\{1,2,3\}, 1}>0$ and $\left.t_{\{1,2\}, 1}=t_{\{1,3\}, 1}>0\right)$ but the tariff on good 1 is negative when the representative of district 1 is in the minority party (i.e., $t_{\{2,3\}, 1}<$ 0 ). The policy outcomes are most extreme when party discipline is totally lacking and converge to free trade as discipline becomes perfect. The bottom panel shows the equilibrium platform and the expected tariff for industry 1 , both of which are positive and monotonically decreasing, as is generally the case.

Figure II depicts another possibility. ${ }^{21}$ Here the parameter values are the same as for Figure I, except that the supply functions are flatter $(\gamma=2$ instead of $\gamma=1)$. Now the tariff on good 1 is positive no matter what the electoral outcome, although smallest (for given $\delta$ ) when the representative of district 1 is not a member of the majority delegation. Again the tariff levels, and also the platform and the expected tariffs, converge monotonically to zero.

We turn next to the distribution of the capital stock. If the districts are homogeneous in their capital ownerships (and hence their industrial structures), tariffs cannot be used to redistribute income, and there is no political gain to be had from protection. The more uneven the distribution, the greater is the scope for tyranny of the majority. This suggests loosely that the protectionist bias may grow with a spread in ownership shares. In fact, we have

Proposition 4. (i) $\partial \tau / \partial \alpha_{j}>\partial \tau / \partial \alpha_{k}$ iff $\alpha_{j}>\alpha_{k}$. (ii) For all $L$, $\partial \bar{t}_{L} / \partial \alpha_{j}>\partial \bar{t}_{L} / \partial \alpha_{k}$ iff $\alpha_{j}>\alpha_{k}$. (iii) For all $g, \partial E\left[t_{L, g}\right] / \partial \alpha_{j}>$ $\partial E\left[t_{L, g}\right] / \partial \alpha_{k}$ iff $\alpha_{j}>\alpha_{k}$.

The proposition has the following implication. Fix any one of the capital ownership parameters, say $\alpha_{3}$. Suppose that $\alpha_{1}>\alpha_{2}$. Now let $\alpha_{1}$ grow. Then $\alpha_{2}$ shrinks by the same amount, because the two must sum to $1-\alpha_{3}$. Part (i) states that this spread of the distribution of capital ownership results in a more protectionist policy announcement. Part (ii) says the spread in ownership shares increases the average tariff for any electoral outcome. Part

21. Still another possibility is that the actual tariff on a good is positive only when the two districts with the largest capital shares are both included in the majority delegation. For example, when $\beta=2, \gamma=1, x^{*}=1$, and $\alpha_{1}=0.4, \alpha_{2}=$ 0.4 , and $\alpha_{3}=0.2, t_{\{1,2\}, 1}>0$ and $t_{\{1,2,3\}, g}>0$ for all finite $\delta$, but $t_{\{1,2\}, 2}=$ $t_{\{1,2\}, 3}<0$ for all finite $\delta$. 

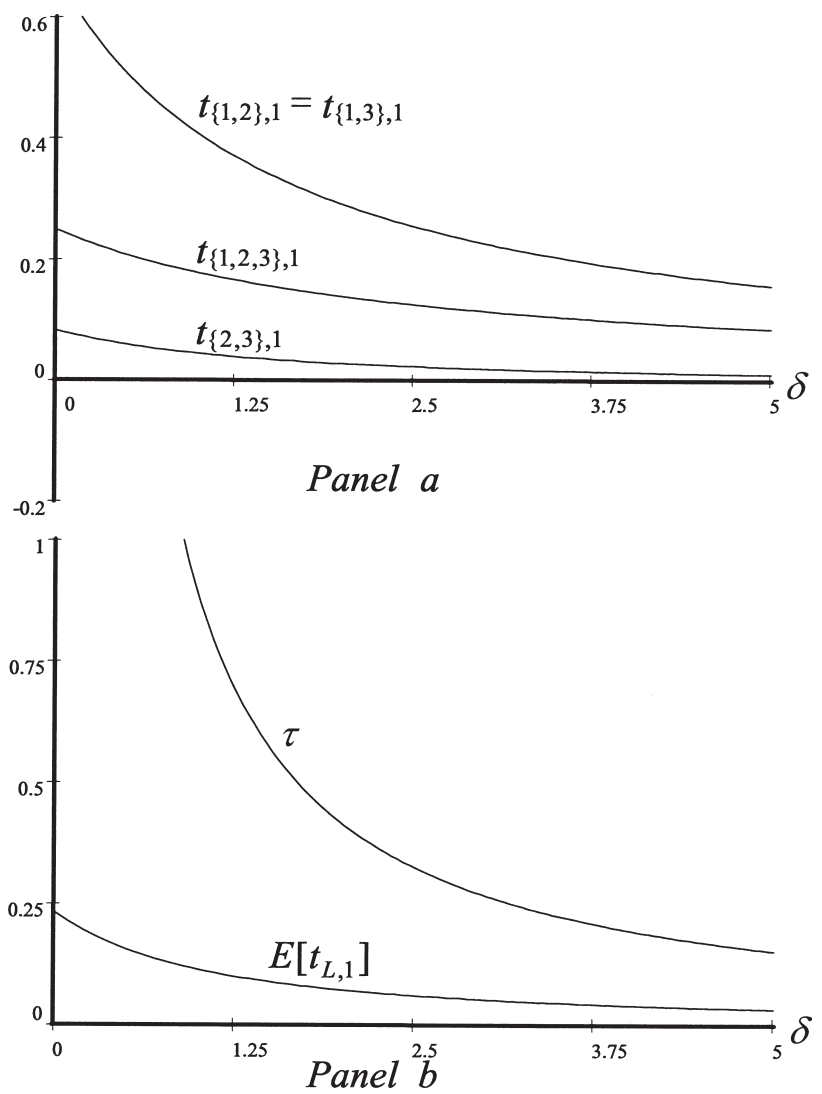

FiguRE II

Positive Protection for All Industries

(iii) states that the expected protection of every industry also rises. Evidently, the protectionist bias is most severe when the ownership of each industry is concentrated in a single district.

Finally, consider the slopes of the demand and supply curves. As $\beta$ rises, the marginal deadweight loss associated with any movement away from free trade grows. From (11) and (12) it is clear that the elected representatives will choose a smaller deviation from free trade in every industry for given $\tau$ the larger is $\beta$. It stands to reason that the announcement will involve less of a protectionist bias, too, because there is less political appeal of using tariffs to redistributive income when the excess burden is large. Indeed, we have found $\partial \tau / \partial \beta<0$ in all of our (many) 
t-gamma.wmf

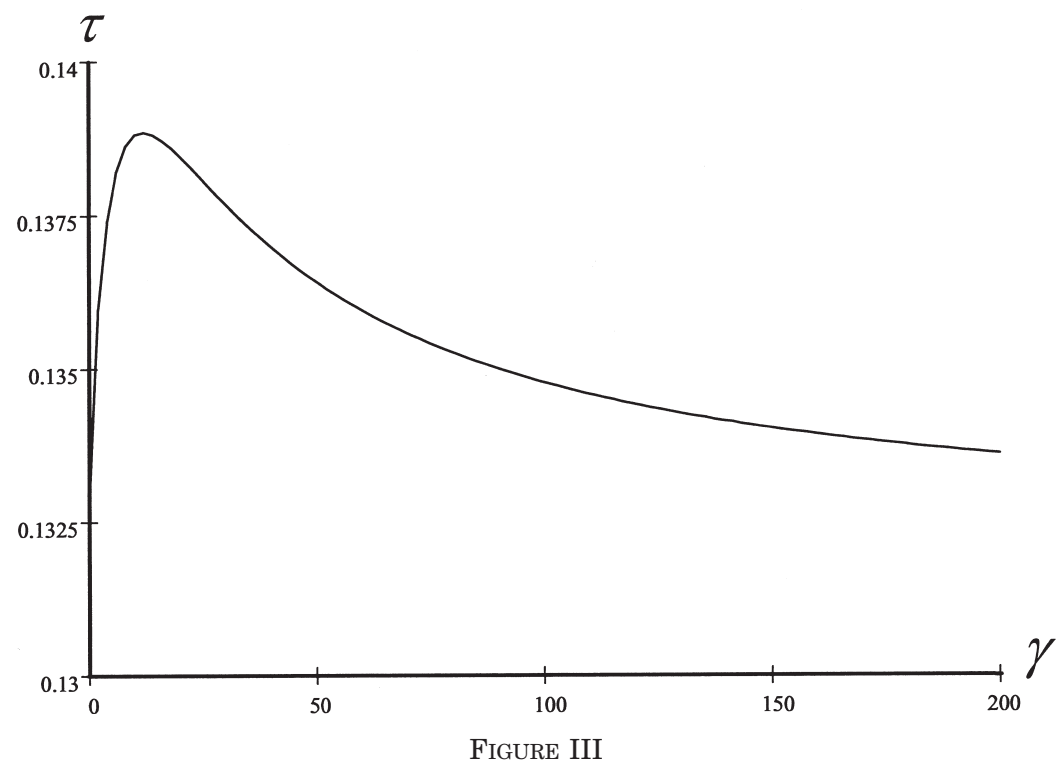

Platform Rises and Declines with $\gamma$

numerical examples, although we have been unable to prove an analytical result. We do know, however, that $\lim _{\beta \rightarrow \infty} \tau=0$, as is apparent from equation (17). If $\partial \tau / \partial \beta<0$, it follows that all positive tariff rates are monotonically decreasing in $\beta$, while the negative rates may increase monotonically or fall first and then rise. In any case, all tariffs approach zero as $\beta$ grows large.

In contrast to an increase in $\beta$, an increase in the responsiveness of output to price has offsetting political implications. On the one hand, an increase in $\gamma$ exacerbates the marginal deadweight loss associated with any movement of the trade policy variable away from free trade. On the other hand, trade policy becomes a more effective redistributive tool as $\gamma$ grows larger. We find that a change in $\gamma$ holding $x^{*}$ constant has an ambiguous effect on the tariff announcement. ${ }^{22}$ For example, Figure III depicts the relationship between the platform and $\gamma$ when $\beta=0, \delta=10, x^{*}=$ 100 and $\alpha_{1}=0.4, \alpha_{2}=0.3$, and $\alpha_{3}=0.3$. Clearly, the announce-

22. An increase in $\gamma$ with $x^{*}$ constant corresponds to a rotation of the supply curve around the free-trade production level. 
ment becomes more protectionist with $\gamma$ when $\gamma$ is small, but it tends toward free trade when $\gamma$ is large. Even if the announced $\tau$ falls monotonically to zero-as it does for many parameter values-the realized tariffs may display a nonmonotonic relationship to the supply responsiveness. It is even possible that a majority delegation representing the two districts with the smallest ownership shares in an industry will set a negative tariff for that good if $\gamma$ is small but a positive tariff if $\gamma$ is large, so that the tariff rises, then falls, then asymptotes to zero, as $\gamma$ ranges from zero to infinity. ${ }^{23}$

\section{Conclusions}

We have developed a novel model of campaigns, elections, and the policy-making process. In our model, national political parties aim to maximize their probability of controlling the legislature, while elected legislators seek to serve the interests of voters in their own districts. The parties announce policy platforms as in a Downsian world, but these do not fully commit the elected representatives. The legislators can deviate from their parties' position in order to serve their constituents, but they pay a political cost that varies with the size of any such deviation. Thus, the model distinguishes "policy rhetoric" from "policy reality."

When we apply the model to trade policy formation, we find a protectionist bias in the equilibrium outcome of majoritarian systems. We define protection as a policy that raises the domestic price of a tradable good above the international price level. Thus, protection involves positive import tariffs or export subsidies. We find that announced trade policies always involve nonnegative tariffs or export subsidies, and that the random electoral process yields an expected policy with similar properties. Both positions and expected outcomes involve positive protection whenever output responds positively to price, districts differ in their ownership shares of the industry-specific capital stocks and party discipline is less than perfect. The protectionist bias reflects the convexity of industry profits as a function of price, and it arises whenever national parties cannot precommit to a policy and when the majority delegation does not fully incorporate the preferences of 0.05 .

23. This is true, for example, when $\beta=2, \delta=1, \alpha_{1}=0.65, \alpha_{2}=0.35$, and $\alpha_{3}=$ 
the minority in its policy deliberations. The protectionist bias is larger the more unequal the distribution of industry-specific capital stocks. Under these circumstances one expects a smaller protectionist bias in countries with better capital markets, which allow individuals to better diversify asset holdings and thereby reduce their exposure to electoral risks.

Our analysis provides yet another demonstration of the importance of political institutions for economic policy outcomes. We have focused here on differences in "party discipline," which we associate with the size of penalties that a national party can impose on individual legislators if the latter choose to deviate from the parties' announced positions when they are in a position to set policy. We do not model the instruments of party discipline, but rather treat this institutional feature of the political system parametrically. A strengthening of party discipline causes both the tariff (or export subsidy) announcements and the expected tariff outcome to converge toward free trade. Thus, among countries with majoritarian electoral systems, we would expect on average to find outcomes closer to free trade in those with institutions that impose greater party discipline.

Our paper joins a very small literature on the comparative politics of trade policy. We hope that future research by us and others will elaborate on the determinants of party discipline, and introduce other important differences in political institutions, such as between presidential and parliamentary regimes and between systems with majoritarian elections versus some form of proportional representation. If, for example, one takes the view that proportional representation leads to the election of legislators who maximize aggregate welfare, because their election is not tied to particular geographic or economic interests, then our model predicts higher average rates of protection in countries with majoritarian elections than in countries with proportional representation. ${ }^{24}$ By introducing political features such as these, we can gain a better understanding of cross-country differences in trade policies.

24. We believe, however, that it is necessary to model explicitly the construction of party lists in systems with proportional representation in order to make an informed comparison between majoritarian and proportional representation, because some procedures for constructing party lists generate biases of their own. In Israel, for example, the lists of the large parties are determined by internal elections. As a result, those who are selected for the party list represent disproportionately the interests of those citizens who were responsible for their victory in the internal party election. 
APPENDIX

\section{First-Order Conditions}

We first derive equations that hold if and only if the firstorder conditions (15) are satisfied. These equations will be used to show that the equilibrium platform is given by (17). To this end, first note that we can use (13) together with (11) and (12) to derive $\Delta_{j}$ as a function of $\left(\rho_{k}, \rho_{l}, \tau^{A}, \tau^{B}\right)$. Denote this functional relationship as $\Delta_{j}\left(\rho_{k}, \rho_{l}, \tau^{A}, \tau^{B}\right)$. Substituting this function into (14) gives $\rho_{j}=F\left[\frac{\Delta_{j}\left(\rho_{k}, \rho_{l}, \tau^{A}, \tau^{B}\right)}{\rho_{k}\left(1-\rho_{l}\right)+\rho_{l}\left(1-\rho_{k}\right)}\right]$, for $j, k, l$ different from each other.

This is the system from which we can calculate $\partial \rho_{j} / \partial \tau_{g}^{A}$ and $\partial \rho_{j} / \partial \tau_{g}^{B}$. For a symmetric equilibrium it is enough to calculate $\partial \rho_{j} / \partial \tau_{g}^{A}$.

Differentiating this system of three equations with respect to the probabilities $\rho_{1}, \rho_{2}, \rho_{3}$ and with respect to $\tau_{g}^{A}$, and evaluating the result at the symmetric equilibrium point $\tau_{g}^{K}=\tau$ for all $K$ and $g$, and $\rho_{j}=1 / 2$ for all $j$, we obtain

$$
E\left(\begin{array}{c}
\frac{\partial \rho_{1}}{\partial \tau_{g}^{A}} \\
\frac{\partial \rho_{2}}{\partial \tau_{g}^{A}} \\
\frac{\partial \rho_{3}}{\partial \tau_{g}^{A}}
\end{array}\right)=2 F^{\prime}(0)\left(\begin{array}{c}
\frac{\partial \Delta_{1}}{\partial \tau_{g}^{A}} \\
\frac{\partial \Delta_{2}}{\partial \tau_{g}^{A}} \\
\frac{\partial \Delta_{3}}{\partial \tau_{g}^{A}}
\end{array}\right)
$$

where $E$ is the matrix

$$
E=\left(\begin{array}{cccc}
1 & -2 F^{\prime}(0) \frac{\partial \Delta_{1}}{\partial \rho_{2}} & -2 F^{\prime}(0) \frac{\partial \Delta_{1}}{\partial \rho_{3}} \\
-2 F^{\prime}(0) \frac{\partial \Delta_{2}}{\partial \rho_{1}} & 1 & -2 F^{\prime}(0) \frac{\partial \Delta_{2}}{\partial \rho_{3}} \\
-2 F^{\prime}(0) \frac{\partial \Delta_{3}}{\partial \rho_{1}} & -2 F^{\prime}(0) \frac{\partial \Delta_{3}}{\partial \rho_{2}} & 1
\end{array}\right) .
$$

Next note that at the equilibrium point

$$
\frac{\partial \Delta_{j}}{\partial \rho_{k}}=\left[3 V_{j}\left(\mathbf{t}_{\{1,2,3\}}^{A}\right)-3 V_{j}\left(\mathbf{t}_{\{k, l\}}^{A}\right)\right]+\left[3 V_{j}\left(\mathbf{t}_{\{j, k\}}^{A}\right)-3 V_{j}\left(\mathbf{t}_{\{j, l\}}^{A}\right)\right]
$$




$$
\begin{array}{r}
=Q(\tau)+3 \sum_{g=1}^{3} \alpha_{j g} \Pi\left(p^{*}+\frac{\left(1 / 3-\alpha_{l g}\right) x^{*}+\delta \tau}{(2 / 3)(\beta+\gamma)+\delta-\gamma\left(1 / 3-\alpha_{l g}\right)}\right) \\
-3 \sum_{g=1}^{3} \alpha_{j g} \Pi\left(p^{*}+\frac{\left(1 / 3-\alpha_{k g}\right) x^{*}+\delta \tau}{(2 / 3)(\beta+\gamma)+\delta-\gamma\left(1 / 3-\alpha_{k g}\right)}\right), j \notin\{k, l\},
\end{array}
$$

where

$$
\begin{array}{r}
Q(\tau)=3 \Pi\left(p^{*}+\frac{\delta \tau}{\beta+\gamma+\delta}\right)+3 Z\left(\frac{\delta \tau}{\beta+\gamma+\delta}\right) \\
-3 \sum_{g=1}^{3} \alpha_{g} \Pi\left(p^{*}+\frac{\left(1 / 3-\alpha_{g}\right) x^{*}+\delta \tau}{(2 / 3)(\beta+\gamma)+\delta-\gamma\left(1 / 3-\alpha_{g}\right)}\right) \\
-\sum_{g=1}^{3} Z\left(\frac{\left(1 / 3-\alpha_{g}\right) x^{*}+\delta \tau}{(2 / 3)(\beta+\gamma)+\delta-\gamma\left(1 / 3-\alpha_{g}\right)}\right)
\end{array}
$$

and

$$
Z(t)=S\left(p^{*}+t\right)+t m\left(p^{*}+t\right) .
$$

We calculate

$$
\begin{aligned}
& \frac{\partial \Delta_{2}}{\partial \rho_{1}}+\frac{\partial \Delta_{3}}{\partial \rho_{1}}=2 Q(\tau) \\
& +3 \sum_{g=1}^{3} \alpha_{2 g} \Pi\left(p^{*}+\frac{\left(1 / 3-\alpha_{3 g}\right) x^{*}+\delta \tau}{(2 / 3)(\beta+\gamma)+\delta-\gamma\left(1 / 3-\alpha_{3 g}\right)}\right) \\
& -3 \sum_{g=1}^{3} \alpha_{2 g} \Pi\left(p^{*}+\frac{\left(1 / 3-\alpha_{1 g}\right) x^{*}+\delta \tau}{(2 / 3)(\beta+\gamma)+\delta-\gamma\left(1 / 3-\alpha_{1 g}\right)}\right) \\
& +3 \sum_{g=1}^{3} \alpha_{3 g} \Pi\left(p^{*}+\frac{\left(1 / 3-\alpha_{2 g}\right) x^{*}+\delta \tau}{(2 / 3)(\beta+\gamma)+\delta-\gamma\left(1 / 3-\alpha_{2 g}\right)}\right) \\
& \quad-3 \sum_{g=1}^{3} \alpha_{3 g} \Pi\left(p^{*}+\frac{\left(1 / 3-\alpha_{1 g}\right) x^{*}+\delta \tau}{(2 / 3)(\beta+\gamma)+\delta-\gamma\left(1 / 3-\alpha_{1 g}\right)}\right),
\end{aligned}
$$


or

$$
\begin{aligned}
& \frac{\partial \Delta_{2}}{\partial \rho_{1}}+\frac{\partial \Delta_{3}}{\partial \rho_{1}}=2 Q(\tau) \\
& -3 \sum_{g=1}^{3}\left(1-\alpha_{g}\right) \Pi\left(p^{*}+\frac{\left(1 / 3-\alpha_{g}\right) x^{*}+\delta \tau}{(2 / 3)(\beta+\gamma)+\delta-\gamma\left(1 / 3-\alpha_{g}\right)}\right) \\
& +3 \sum_{g=1}^{3} \alpha_{2 g} \Pi\left(p^{*}+\frac{\left(1 / 3-\alpha_{3 g}\right) x^{*}+\delta \tau}{(2 / 3)(\beta+\gamma)+\delta-\gamma\left(1 / 3-\alpha_{3 g}\right)}\right) \\
& \quad+3 \sum_{g=1}^{3} \alpha_{3 g} \Pi\left(p^{*}+\frac{\left(1 / 3-\alpha_{2 g}\right) x^{*}+\delta \tau}{(2 / 3)(\beta+\gamma)+\delta-\gamma\left(1 / 3-\alpha_{2 g}\right)}\right) .
\end{aligned}
$$

Since

$$
\begin{aligned}
& \sum_{g=1}^{3} \alpha_{2 g} \Pi\left(p^{*}+\frac{\left(1 / 3-\alpha_{3 g}\right) x^{*}+\delta \tau}{(2 / 3)(\beta+\gamma)+\delta-\gamma\left(1 / 3-\alpha_{3 g}\right)}\right) \\
&+\sum_{g=1}^{3} \alpha_{3 g} \Pi\left(p^{*}+\frac{\left(1 / 3-\alpha_{2 g}\right) x^{*}+\delta \tau}{(2 / 3)(\beta+\gamma)+\delta-\gamma\left(1 / 3-\alpha_{2 g}\right)}\right) \\
&=\alpha_{2} \Pi\left(p^{*}+\frac{\left(1 / 3-\alpha_{3}\right) x^{*}+\delta \tau}{(2 / 3)(\beta+\gamma)+\delta-\gamma\left(1 / 3-\alpha_{3}\right)}\right) \\
&+\alpha_{1} \Pi\left(p^{*}+\frac{\left(1 / 3-\alpha_{2}\right) x^{*}+\delta \tau}{(2 / 3)(\beta+\gamma)+\delta-\gamma\left(1 / 3-\alpha_{2}\right)}\right) \\
& \quad \alpha_{3} \Pi\left(p^{*}+\frac{\left(1 / 3-\alpha_{1}\right) x^{*}+\delta \tau}{(2 / 3)(\beta+\gamma)+\delta-\gamma\left(1 / 3-\alpha_{1}\right)}\right) \\
&+\alpha_{3} \Pi\left(p^{*}+\frac{\left(1 / 3-\alpha_{2}\right) x^{*}+\delta \tau}{(2 / 3)(\beta+\gamma)+\delta-\gamma\left(1 / 3-\alpha_{2}\right)}\right) \\
&+\alpha_{2} \Pi\left(p^{*}+\frac{\left(1 / 3-\alpha_{1}\right) x^{*}+\delta \tau}{(2 / 3)(\beta+\gamma)+\delta-\gamma\left(1 / 3-\alpha_{1}\right)}\right) \\
&+\alpha_{1} \Pi\left(p^{*}+\frac{\left(1 / 3-\alpha_{3}\right) x^{*}+\delta \tau}{(2 / 3)(\beta+\gamma)+\delta-\gamma\left(1 / 3-\alpha_{3}\right)}\right) \\
&= \sum_{g=1}\left(1-\alpha_{g}\right) \Pi\left(p^{*}+\frac{\left(1 / 3-\alpha_{g}\right) x^{*}+\delta \tau}{(2 / 3)(\beta+\gamma)+\delta-\gamma\left(1 / 3-\alpha_{g}\right)}\right)
\end{aligned}
$$

we find that $\partial \Delta_{2} / \partial \rho_{1}+\partial \Delta_{3} / \partial \rho_{1}=2 Q(\tau)$. Similarly, $\partial \Delta_{j} / \partial \rho_{l}+$ $\partial \Delta_{k} / \partial \rho_{l}=2 Q(\tau)$, for other $j, k, l$ that are different from one 
another. This implies that $\mathbf{1}^{T} E=\left[1-4 F^{\prime}(0) Q(\tau)\right](1,1,1)$, where $\mathbf{1}$ is a column vector of ones, and therefore $\mathbf{1}^{T}=(1,1,1)$. We assume that $0<F^{\prime}(0)<1 / 4 Q(\tau)$, where $\tau$ is given by (17). That is, $F^{\prime}(0)$ is small enough, and its upper limit is a function of the model's parameters. ${ }^{25}$ In this event we can multiply (A1) by $\mathbf{1}^{T}$ from the left to obtain

$$
\sum_{j=1}^{3} \frac{\partial \rho_{j}}{\partial \tau_{g}^{A}}=\frac{2 F^{\prime}(0)}{1-4 F^{\prime}(0) Q(\tau)} \sum_{j=1}^{3} \frac{\partial \Delta_{j}}{\partial \tau_{g}^{A}} \quad \text { for every } g .
$$

This equation, together with the restriction $0<F^{\prime}(0)<1 / 4 Q(\tau)$, implies that the first-order conditions (15) are satisfied if and only if

$$
\sum_{j=1}^{3} \frac{\partial \Delta_{j}}{\partial \tau_{g}^{A}}=0 \quad \text { for all } g .
$$

We now use this condition to derive the equilibrium announcement $\tau$.

At the equilibrium point, where $\tau_{g}^{A}=\tau_{g}^{B}=\tau$ for all $g$ and $\rho_{j}=$ $1 / 2$ for all $j$,

$$
\begin{aligned}
\frac{4}{3} \frac{\partial \Delta_{j}}{\partial \tau_{g}^{A}}= & {\left[\left(\alpha_{j g}-\frac{1}{3}\right)\left(x^{*}+\gamma \frac{\delta \tau}{\beta+\gamma+\delta}\right)\right.} \\
& \left.-\frac{1}{3}(\beta+\gamma) \frac{\delta \tau}{\beta+\gamma+\delta}\right] \frac{\delta}{\beta+\gamma+\delta} \\
& -\left[\left(\alpha_{j g}-\frac{1}{3}\right)\left(x^{*}+\gamma \frac{\left(1 / 3-\alpha_{j g}\right) x^{*}+\delta \tau}{(2 / 3)(\beta+\gamma)+\delta-\gamma\left(1 / 3-\alpha_{j g}\right)}\right)\right. \\
& \left.-\frac{1}{3}(\beta+\gamma) \frac{\left(1 / 3-\alpha_{j g}\right) x^{*}+\delta \tau}{(2 / 3)(\beta+\gamma)+\delta-\gamma\left(1 / 3-\alpha_{j g}\right)}\right] \\
& \times \frac{\delta}{2 / 3(\beta+\gamma)+\delta-\gamma\left(1 / 3-\alpha_{j g}\right)} \\
& +\left[\left(\alpha_{j g}-\frac{1}{3}\right)\left(x^{*}+\gamma \frac{\left(1 / 3-\alpha_{l g}\right) x^{*}+\delta \tau}{(2 / 3)(\beta+\gamma)+\delta-\gamma\left(1 / 3-\alpha_{l g}\right)}\right)\right. \\
& \left.-\frac{1}{3}(\beta+\gamma) \frac{\left(1 / 3-\alpha_{l g}\right) x^{*}+\delta \tau}{(2 / 3)(\beta+\gamma)+\delta-\gamma\left(1 / 3-\alpha_{l g}\right)}\right]
\end{aligned}
$$

25. Our simulations indicate that $F^{\prime}(0)$ has to be small for the symmetric equilibrium to exist. When $F^{\prime}(0)$ is large, the second-order conditions of the best response of party $A$ to $B$ 's platform are not satisfied at the proposed symmetric equilibrium point. 


$$
\begin{aligned}
& \times \frac{\delta}{(2 / 3)(\beta+\gamma)+\delta-\gamma\left(1 / 3-\alpha_{l g}\right)} \\
& +\left[\left(\alpha_{j g}-\frac{1}{3}\right)\left(x^{*}+\gamma \frac{\left(1 / 3-\alpha_{k g}\right) x^{*}+\delta \tau}{(2 / 3)(\beta+\gamma)+\delta-\gamma\left(1 / 3-\alpha_{k g}\right)}\right)\right. \\
& \left.-\frac{1}{3}(\beta+\gamma) \frac{\left(1 / 3-\alpha_{k g}\right) x^{*}+\delta \tau}{(2 / 3)(\beta+\gamma)+\delta-\gamma\left(1 / 3-\alpha_{k g}\right)}\right] \\
& \times \frac{\delta}{(2 / 3)(\beta+\gamma)+\delta-\gamma\left(1 / 3-\alpha_{k g}\right)} \\
& =\left[\left(\alpha_{j g}-\frac{1}{3}\right)\left(x^{*}+\gamma \frac{\delta \tau}{\beta+\gamma+\delta}\right)\right. \\
& \left.-\frac{1}{3}(\beta+\gamma) \frac{\delta \tau}{\beta+\gamma+\delta}\right] \frac{\delta}{\beta+\gamma+\delta} \\
& -\left[\left(\alpha_{j g}-\frac{1}{3}\right)\left(x^{*}+\gamma \frac{\left(1 / 3-\alpha_{j g}\right) x^{*}+\delta \tau}{(2 / 3)(\beta+\gamma)+\delta-\gamma\left(1 / 3-\alpha_{j g}\right)}\right)\right. \\
& \left.-\frac{1}{3}(\beta+\gamma) \frac{\left(1 / 3-\alpha_{j g}\right) x^{*}+\delta \tau}{(2 / 3)(\beta+\gamma)+\delta-\gamma\left(1 / 3-\alpha_{j g}\right)}\right] \\
& \times \frac{2 \delta}{(2 / 3)(\beta+\gamma)+\delta-\gamma\left(1 / 3-\alpha_{j g}\right)} \\
& +\left(\alpha_{j g}-\frac{1}{3}\right) \sum_{h=1}^{3}\left(x^{*}+\gamma \frac{\left(1 / 3-\alpha_{h}\right) x^{*}+\delta \tau}{(2 / 3)(\beta+\gamma)+\delta-\gamma\left(1 / 3-\alpha_{h}\right)}\right) \\
& \times \frac{\delta}{(2 / 3)(\beta+\gamma)+\delta-\gamma\left(1 / 3-\alpha_{h}\right)} \\
& -\frac{1}{3} \delta(\beta+\gamma) \sum_{h=1}^{3} \frac{\left(1 / 3-\alpha_{h}\right) x^{*}+\delta \tau}{\left[(2 / 3)(\beta+\gamma)+\delta-\gamma\left(1 / 3-\alpha_{h}\right)\right]^{2}} .
\end{aligned}
$$

It follows that $\sum_{j=1}^{3} \partial \Delta_{j} / \partial \tau_{g}^{A}=0$ if and only if

$$
\begin{aligned}
& \sum_{l=1}^{3} 2\left(\frac{1}{3}-\alpha_{l}\right)\left(x^{*}+\gamma \frac{\left(1 / 3-\alpha_{l}\right) x^{*}+\delta \tau}{(2 / 3)(\beta+\gamma)+\delta-\gamma\left(1 / 3-\alpha_{l}\right)}\right) \\
& \quad \times \frac{\delta}{(2 / 3)(\beta+\gamma)+\delta-\gamma\left(1 / 3-\alpha_{l}\right)}-\frac{1}{3}(\beta+\gamma) \\
& \quad \times \sum_{l=1}^{3} \frac{\left[\left(1 / 3-\alpha_{l}\right) x^{*}+\delta \tau\right] \delta}{\left[(2 / 3)(\beta+\gamma)+\delta-\gamma\left(1 / 3-\alpha_{l}\right)\right]^{2}}-\frac{(\beta+\gamma) \delta^{2} \tau}{(\beta+\gamma+\delta)^{2}}=0 .
\end{aligned}
$$


This equation is the same as (16), because

$$
\begin{gathered}
t_{\{-l, g}^{A}=\frac{\left(1 / 3-\alpha_{l g}\right) x^{*}+\delta \tau_{g}^{A}}{(2 / 3)(\beta+\gamma)+\delta-\gamma\left(1 / 3-\alpha_{l g}\right)}, \\
\frac{\partial t_{\{-l, g}^{A}}{\partial \tau_{g}^{A}}=\frac{\delta}{(2 / 3)(\beta+\gamma)+\delta-\gamma\left(1 / 3-\alpha_{l g}\right)}, \\
t_{\{1,2,3\}, g}^{A}=\frac{\delta \tau_{g}^{A}}{\beta+\gamma+\delta},
\end{gathered}
$$

and

$$
\frac{\partial t_{\{1,2,3\}, g}^{A}}{\partial \tau_{g}^{A}}=\frac{\delta}{\beta+\gamma+\delta} .
$$

It follows from this equation that for $\delta>0$, the first-order condition is satisfied if and only if (17) holds.

We now show that the denominator of (17) is positive when Assumption 1 is satisfied for all $\delta \geq 0$. Let

$$
D(\delta)=\frac{\beta+\gamma}{(\beta+\gamma+\delta)^{2}}+\sum_{l=1}^{3} \frac{1 / 3(\beta+\gamma)-2\left(1 / 3-\alpha_{l}\right) \gamma}{\left[(2 / 3) \beta+\delta+(2 / 3) \gamma-\left(1 / 3-\alpha_{l}\right) \gamma\right]^{2}}
$$

be the term in the curly brackets in the denominator of (17). We need to show that Assumption 1 implies that $D(\delta)>0$ for all $\delta>0$.

Suppose not; i.e., suppose that $D(\delta)<0$ for some positive value of $\delta$. Assumption 1 implies that $D(0)>0$. Since $D(\cdot)$ is continuous in $\delta$, it can become negative for higher values of $\delta$ only if there exists a $\tilde{\delta}>0$ such that $D(\tilde{\delta})=0$ and $D^{\prime}(\tilde{\delta})<0$. Let $\delta_{0}$ be the smallest $\tilde{\delta}$ for which this is true.

We calculate

$D^{\prime}(\delta)=-2\left[\frac{\beta+\gamma}{(\beta+\gamma+\delta)^{3}}+\sum_{l=1}^{3} \frac{1 / 3(\beta+\gamma)-2\left(1 / 3-\alpha_{l}\right) \gamma}{\left[(2 / 3) \beta+\delta+(2 / 3) \gamma-\left(1 / 3-\alpha_{l}\right) \gamma\right]^{3}}\right]$.

Now note that

$$
\frac{\beta+\gamma}{(\beta+\gamma+\delta)^{3}}<\frac{\beta+\gamma}{[(1 / 2) \beta+\delta+(1 / 2) \gamma](\beta+\gamma+\delta)^{2}},
$$

and 


$$
\begin{gathered}
\frac{(1 / 3)(\beta+\gamma)-2\left(1 / 3-\alpha_{l}\right) \gamma}{\left[(2 / 3) \beta+\delta+(2 / 3) \gamma-\left(1 / 3-\alpha_{l}\right) \gamma\right]^{3}} \\
-\frac{(1 / 3)(\beta+\gamma)-2\left(1 / 3-\alpha_{l}\right) \gamma}{[(1 / 2) \beta+\delta+(1 / 2) \gamma]\left[(2 / 3) \beta+\delta+(2 / 3) \gamma-\left(1 / 3-\alpha_{l}\right) \gamma\right]^{2}} \\
=-\frac{\left[(1 / 3)(\beta+\gamma)-2\left(1 / 3-\alpha_{l}\right) \gamma\right]^{2}}{2[(1 / 2) \beta+\delta+(1 / 2) \gamma]\left[(2 / 3) \beta+\delta+(2 / 3) \gamma-\left(1 / 3-\alpha_{l}\right) \gamma\right]^{3}} \\
<0 \quad \text { for every } l .
\end{gathered}
$$

Therefore,

$$
D^{\prime}(\delta)>-2 D(\delta) /[(1 / 2) \beta+\delta+(1 / 2) \gamma]
$$

for every $\delta>0$. But since $D\left(\delta_{0}\right)=0$, this inequality implies that $D^{\prime}\left(\delta_{0}\right)>0$, which contradicts our supposition $D^{\prime}\left(\delta_{0}\right)<0$. It follows that no such $\tilde{\delta}$ exists and $D(\delta)>0$ for all $\delta>0$.

Proof of Proposition 1

To prove part (i), first note that if $\alpha_{l}=1 / 3$ for all $l$ or $\gamma=0$, then

$$
\sum_{l=1}^{3} \frac{\left(1 / 3-\alpha_{l}\right)}{\left[(2 / 3) \beta+\delta+(2 / 3) \gamma-\left(1 / 3-\alpha_{l}\right) \gamma\right]^{2}}=0 .
$$

This implies, by (17), that $\tau=0$. Next note that if $\delta>0, \alpha_{l} \neq 1 / 3$ for some $l$ and $\gamma>0$, then

$$
\begin{aligned}
& \frac{1 / 3-\alpha_{l}}{\left[(2 / 3) \beta+\delta+(2 / 3) \gamma-\left(1 / 3-\alpha_{l}\right) \gamma\right]^{2}} \\
& \quad>\frac{1 / 3-\alpha_{l}}{[(2 / 3) \beta+\delta+(2 / 3) \gamma-(1 / 3-1 / 3) \gamma]^{2}} \quad \text { for } \alpha_{l} \neq \frac{1}{3}
\end{aligned}
$$

and

$$
\begin{aligned}
& \frac{1 / 3-\alpha_{l}}{\left[(2 / 3) \beta+\delta+(2 / 3) \gamma-\left(1 / 3-\alpha_{l}\right) \gamma\right]^{2}} \\
& \quad=\frac{1 / 3-\alpha_{l}}{[(2 / 3) \beta+\delta+(2 / 3) \gamma-(1 / 3-1 / 3) \gamma]^{2}} \quad \text { for } \alpha_{l}=\frac{1}{3} .
\end{aligned}
$$

Therefore, 


$$
\begin{aligned}
& \sum_{l=1}^{3} \frac{\left(1 / 3-\alpha_{l}\right)}{\left[(2 / 3) \beta+\delta+(2 / 3) \gamma-\left(1 / 3-\alpha_{l}\right) \gamma\right]^{2}} \\
& \quad>\sum_{l=1}^{3} \frac{1 / 3-\alpha_{l}}{[(2 / 3) \beta+\delta+(2 / 3) \gamma]^{2}}=0 .
\end{aligned}
$$

Since the denominator of (17) is positive under Assumption 1, this inequality implies that $\tau>0$.

To prove part (ii), note from (17) that

$$
\lim _{\delta \rightarrow \infty} \tau=\frac{2 x^{*} \Sigma_{l=1}^{3}\left(1 / 3-\alpha_{l}\right)}{\beta+\gamma+\Sigma_{l=1}^{3}\left[(1 / 3)(\beta+\gamma)-2\left(1 / 3-\alpha_{l}\right) \gamma\right]}=0 .
$$

Proof of Proposition 2

To prove part (i), note from part (i) of Proposition 1 that $\alpha_{l}=$ $1 / 3$ for all $l$ implies $\tau=0$. It is then evident from (11) and (12) that $t_{L, g}=0$ for every majority $L$.

Next consider part (ii). Equations (11) and (12) imply that $\lim _{\delta \rightarrow \infty} t_{L, g}=\lim _{\delta \rightarrow \infty} \tau$ for every majority $L$. But $\lim _{\delta \rightarrow \infty} \tau=0$ according to part (ii) of Proposition 1. Therefore, $\lim _{\delta \rightarrow \infty} t_{L, g}=0$ for all majorities $L$.

Finally, consider part (iii). For finite $\delta>0$ the equilibrium platform is $\tau=0$ when either $\alpha_{l}=1 / 3$ for all $l$ or $\gamma=0$, as stated in part (i) of Proposition 1. Equations (18) and (19) then imply that $\bar{t}_{L}=0$ for all majorities $L$. Moreover, if $\alpha_{l} \neq 1 / 3$ for some $l$ and $\gamma>0$, then $\tau>0$ by part (i) of Proposition 1. In this case, (18) implies that $\bar{t}_{\{1,2,3\}}>0$, while (19) implies that

$$
\begin{aligned}
\bar{t}_{\{j, k\}}>\frac{1}{3} \sum_{l=1}^{3} \frac{\left(1 / 3-\alpha_{l}\right) x^{*}}{(2 / 3)(\beta+\gamma)+\delta-\gamma\left(1 / 3-\alpha_{l}\right)} \\
>\frac{1}{3} \sum_{l=1}^{3} \frac{\left(1 / 3-\alpha_{l}\right) x^{*}}{(2 / 3)(\beta+\gamma)+\delta-\gamma(1 / 3-1 / 3)}=0 .
\end{aligned}
$$

That is, $\bar{t}_{\{j, k\}}>0$.

Proof of Proposition 3

To prove part (i), note from (17) that if $\delta>0, \alpha_{l} \neq 1 / 3$ for some $l$, and $\gamma>0$, then 
(A6)

$$
\frac{\partial}{\partial \delta} \log \tau=-\frac{D^{\prime}(\delta)}{D(\delta)}+\frac{M^{\prime}(\delta)}{M(\delta)}-\frac{\beta+\gamma}{(\beta+\gamma+2 \delta) \delta},
$$

where $D(\delta)$ is defined in (A3),

(A7) $\quad M(\delta)=\sum_{l=1}^{3} \frac{1 / 3-\alpha_{l}}{\left[(2 / 3) \beta+\delta+(2 / 3) \gamma-\left(1 / 3-\alpha_{l}\right) \gamma\right]^{2}}$

and

(A8) $\quad M^{\prime}(\delta)=-2 \sum_{l=1}^{3} \frac{1 / 3-\alpha_{l}}{\left[(2 / 3) \beta+\delta+(2 / 3) \gamma-\left(1 / 3-\alpha_{l}\right) \gamma\right]^{3}}$.

Therefore, $M^{\prime}(\delta) / M(\delta)-D^{\prime}(\delta) / D(\delta)<0$ is sufficient for $\partial \tau / \partial \delta<0$.

Next note that (11), (12), and (17) imply that

$$
\begin{aligned}
& \frac{4 E\left[t_{L, g}\right]}{x^{*}}=\frac{(\beta+\gamma+2 \delta) M}{D} \\
& \times\left[\frac{1}{\beta+\gamma+\delta}+\sum_{l=1}^{3} \frac{1}{(2 / 3) \beta+\delta+(2 / 3) \gamma-\left(1 / 3-\alpha_{l}\right) \gamma}\right] \\
& \quad+\sum_{l=1}^{3} \frac{1 / 3-\alpha_{l}}{(2 / 3) \beta+\delta+(2 / 3) \gamma-\left(1 / 3-\alpha_{l}\right) \gamma} \quad \text { for } g=1,2,3,
\end{aligned}
$$

where we have dropped the argument $\delta$ from the functions $D$ and $M$, which are given in (A3) and (A7). It follows that

$$
\begin{aligned}
& \frac{4 D}{x^{*} M} \frac{\partial E\left[t_{L, g}\right]}{\partial \delta}=\left[2+(\beta+\gamma+2 \delta)\left(\frac{M^{\prime}}{M}-\frac{D^{\prime}}{D}\right)\right] \\
& \times\left[\frac{1}{\beta+\gamma+\delta}+\sum_{l=1}^{3} \frac{1}{(2 / 3) \beta+\delta+(2 / 3) \gamma-\left(1 / 3-\alpha_{l}\right) \gamma}\right] \\
& -D-(\beta+\gamma+2 \delta)\left[\frac{1}{(\beta+\gamma+\delta)^{2}}\right. \\
& \left.+\sum_{l=1}^{3} \frac{1}{\left[(2 / 3) \beta+\delta+(2 / 3) \gamma-\left(1 / 3-\alpha_{l}\right) \gamma\right]^{2}}\right] \\
= & {\left[2+(\beta+\gamma+2 \delta)\left(\frac{M^{\prime}}{M}-\frac{D^{\prime}}{D}\right)\right] }
\end{aligned}
$$




$$
\begin{aligned}
& \times\left[\frac{1}{\beta+\gamma+\delta}+\sum_{l=1}^{3} \frac{1}{(2 / 3) \beta+\delta+(2 / 3) \gamma-\left(1 / 3-\alpha_{l}\right) \gamma}\right] \\
& -2\left[\frac{1}{\beta+\gamma+\delta}+\sum_{l=1}^{3} \frac{1}{(2 / 3) \beta+\delta+(2 / 3) \gamma-\left(1 / 3-\alpha_{l}\right) \gamma}\right] \\
& =(\beta+\gamma+2 \delta)\left[\frac{1}{\beta+\gamma+\delta}\right. \\
& \left.\quad+\sum_{l=1}^{3} \frac{1}{(2 / 3) \beta+\delta+(2 / 3) \gamma-\left(1 / 3-\alpha_{l}\right) \gamma}\right]\left(\frac{M^{\prime}}{M}-\frac{D^{\prime}}{D}\right),
\end{aligned}
$$

where $D^{\prime}$ and $M^{\prime}$ are given in (A4) and (A8), respectively. Therefore, $\partial E\left[t_{L, g}\right] / \partial \delta<0$ if and only if $M^{\prime} / M-D^{\prime} / D<0$.

We now prove that $M^{\prime} / M-D^{\prime} / D<0$, which is sufficient for $\partial \tau / \partial \delta<0$ and $\partial E\left[t_{L, g}\right] / \partial \delta<0$. To establish this inequality, note that

$$
\frac{D^{\prime}}{D}=-2 \frac{A_{3}+\gamma M^{\prime}}{A_{2}-2 \gamma M}
$$

where

$$
\begin{aligned}
& A_{3}=\frac{\beta+\gamma}{(\beta+\gamma+\delta)^{3}}+\sum_{l=1}^{3} \frac{(1 / 3)(\beta+\gamma)}{\left[(2 / 3) \beta+\delta+(2 / 3) \gamma-\left(1 / 3-\alpha_{l}\right) \gamma\right]^{3}}, \\
& A_{2}=\frac{\beta+\gamma}{(\beta+\gamma+\delta)^{2}}+\sum_{l=1}^{3} \frac{(1 / 3)(\beta+\gamma)}{\left[(2 / 3) \beta+\delta+(2 / 3) \gamma-\left(1 / 3-\alpha_{l}\right) \gamma\right]^{2}} .
\end{aligned}
$$

It follows from (A9) that

$$
\frac{M^{\prime}}{M}-\frac{D^{\prime}}{D}=\frac{A_{2}}{\left(A_{2}-2 \gamma M\right)}\left(\frac{M^{\prime}}{M}+\frac{2 A_{3}}{A_{2}}\right) .
$$

Therefore, the sign of $M^{\prime} / M-D^{\prime} / D$ is the same as the sign of

$$
B=M^{\prime} / M+2 A_{3} / A_{2},
$$

because $A_{2}-2 \gamma M=D>0$. That is, we need to show that $B<$ 0 . But 


$$
\begin{aligned}
& \frac{1}{2} B=\left[\left(\frac{1}{(\beta+\gamma+\delta)^{3}}\right.\right. \\
&+\left.\frac{1}{3} \sum_{l=1}^{3} \frac{1}{\left[(2 / 3) \beta+\delta+(2 / 3) \gamma-\left(1 / 3-\alpha_{l}\right) \gamma\right]^{3}}\right) / \\
&\left.\left(\frac{1}{(\beta+\gamma+\delta)^{2}}+\frac{1}{3} \sum_{l=1}^{3} \frac{1}{\left[(2 / 3) \beta+\delta+(2 / 3) \gamma-\left(1 / 3-\alpha_{l}\right) \gamma\right]^{2}}\right)\right] \\
&-\left[\left(\sum_{l=1}^{3} \frac{1 / 3-\alpha_{l}}{\left[(2 / 3) \beta+\delta+(2 / 3) \gamma-\left(1 / 3-\alpha_{l}\right) \gamma\right]^{3}}\right) /\right. \\
&\left.\left(\sum_{l=1}^{3} \frac{1 / 3-\alpha_{l}}{\left[(2 / 3) \beta+\delta+(2 / 3) \gamma-\left(1 / 3-\alpha_{l}\right) \gamma\right]^{2}}\right)\right],
\end{aligned}
$$

which implies that the sign of $B$ is the same as the sign of $C$, where

$$
\begin{aligned}
& C= \frac{1}{(\beta+\gamma+\delta)^{3}} \sum_{l=1}^{3} \frac{1 / 3-\alpha_{l}}{\left[(2 / 3) \beta+\delta+(2 / 3) \gamma-\left(1 / 3-\alpha_{l}\right) \gamma\right]^{2}} \\
&-\frac{1}{(\beta+\gamma+\delta)^{2}} \sum_{l=1}^{3} \frac{1 / 3-\alpha_{l}}{\left[(2 / 3) \beta+\delta+(2 / 3) \gamma-\left(1 / 3-\alpha_{l}\right) \gamma\right]^{3}} \\
&+\frac{1}{3}\left(\sum_{l=1}^{3} \frac{1}{\left[(2 / 3) \beta+\delta+(2 / 3) \gamma-\left(1 / 3-\alpha_{l}\right) \gamma\right]^{3}}\right) \\
& \times\left(\sum_{l=1}^{3} \frac{1 / 3-\alpha_{l}}{\left[(2 / 3) \beta+\delta+(2 / 3) \gamma-\left(1 / 3-\alpha_{l}\right) \gamma\right]^{2}}\right) \\
& \frac{1}{3}\left(\sum_{l=1}^{3} \frac{1}{\left[(2 / 3) \beta+\delta+(2 / 3) \gamma-\left(1 / 3-\alpha_{l}\right) \gamma\right]^{2}}\right) \\
& \times\left(\sum_{l=1}^{3} \frac{1 / 3-\alpha_{l}}{\left[(2 / 3) \beta+\delta+(2 / 3) \gamma-\left(1 / 3-\alpha_{l}\right) \gamma\right]^{3}}\right) .
\end{aligned}
$$


Note, however, that

$$
\begin{gathered}
\frac{1}{(\beta+\gamma+\delta)^{3}} \sum_{l=1}^{3} \frac{1 / 3-\alpha_{l}}{\left[(2 / 3) \beta+\delta+(2 / 3) \gamma-\left(1 / 3-\alpha_{l}\right) \gamma\right]^{2}} \\
-\frac{1}{(\beta+\gamma+\delta)^{2}} \sum_{l=1}^{3} \frac{1 / 3-\alpha_{l}}{\left[(2 / 3) \beta+\delta+(2 / 3) \gamma-\left(1 / 3-\alpha_{l}\right) \gamma\right]^{3}}=\frac{1}{(\beta+\gamma+\delta)^{3}} \\
\times \sum_{l=1}^{3} \frac{\left(1 / 3-\alpha_{l}\right)\left[(2 / 3) \beta+\delta+(2 / 3) \gamma-\left(1 / 3-\alpha_{l}\right) \gamma-(\beta+\gamma+\delta)\right.}{\left[(2 / 3) \beta+\delta+(2 / 3) \gamma-\left(1 / 3-\alpha_{l}\right) \gamma\right]^{3}} \\
=-\frac{1}{(\beta+\gamma+\delta)^{3}} \sum_{l=1}^{3} \frac{\gamma\left(1 / 3-\alpha_{l}\right)^{2}+(1 / 3)(\beta+\gamma)\left(1 / 3-\alpha_{l}\right)}{\left[(2 / 3) \beta+\delta+(2 / 3) \gamma-\left(1 / 3-\alpha_{l}\right) \gamma\right]^{3}}<0
\end{gathered}
$$

and

$$
\begin{aligned}
\frac{1}{3}\left(\sum_{l=1}^{3} \frac{1}{\left[(2 / 3) \beta+\delta+(2 / 3) \gamma-\left(1 / 3-\alpha_{l}\right) \gamma\right]^{3}}\right) \\
\quad \times\left(\sum_{l=1}^{3} \frac{1 / 3-\alpha_{l}}{\left[(2 / 3) \beta+\delta+(2 / 3) \gamma-\left(1 / 3-\alpha_{l}\right) \gamma\right]^{2}}\right) \\
\quad-\frac{1}{3}\left(\sum_{l=1}^{3} \frac{1}{\left[(2 / 3) \beta+\delta+(2 / 3) \gamma-\left(1 / 3-\alpha_{l}\right) \gamma\right]^{2}}\right) \\
\quad \times\left(\sum_{l=1}^{3} \frac{1 / 3-\alpha_{l}}{\left[(2 / 3) \beta+\delta+(2 / 3) \gamma-\left(1 / 3-\alpha_{l}\right) \gamma\right]^{3}}\right) \\
=\frac{1}{3} \sum_{l=1}^{3} \frac{1 / 3-\alpha_{l}}{\left[(2 / 3) \beta+\delta+(2 / 3) \gamma-\left(1 / 3-\alpha_{l}\right) \gamma\right]^{3}} \\
\quad \times \sum_{i=1}^{3}\left(\frac{(2 / 3) \beta+\delta+(2 / 3) \gamma-\left(1 / 3-\alpha_{l}\right) \gamma}{\left[(2 / 3) \beta+\delta+(2 / 3) \gamma-\left(1 / 3-\alpha_{i}\right) \gamma\right]^{3}}\right. \\
\left.\quad-\frac{1 / 3-\alpha_{l}}{\left[(2 / 3) \beta+\delta+(2 / 3) \gamma-\left(1 / 3-\alpha_{i}\right) \gamma\right]^{2}}\right) \\
3 \\
\left.=(2 / 3) \gamma-\left(1 / 3-\alpha_{l}\right) \gamma\right]^{3}
\end{aligned}
$$




$$
\begin{aligned}
& \times \sum_{i=1}^{3} \frac{\left(1 / 3-\alpha_{i}\right) \gamma-\left(1 / 3-\alpha_{l}\right) \gamma}{\left[(2 / 3) \beta+\delta+(2 / 3) \gamma-\left(1 / 3-\alpha_{i}\right) \gamma\right]^{3}} \\
&= \frac{1}{3} \gamma\left(\sum_{l=1}^{3} \frac{1 / 3-\alpha_{l}}{\left[(2 / 3) \beta+\delta+(2 / 3) \gamma-\left(1 / 3-\alpha_{l}\right) \gamma\right]^{3}}\right)^{2} \\
&-\frac{1}{3} \gamma\left(\sum_{l=1}^{3} \frac{\left(1 / 3-\alpha_{l}\right)^{2}}{\left[(2 / 3) \beta+\delta+(2 / 3) \gamma-\left(1 / 3-\alpha_{l}\right) \gamma\right]^{3}}\right) \\
& \times\left(\sum_{l=1}^{3} \frac{1}{\left[(2 / 3) \beta+\delta+(2 / 3) \gamma-\left(1 / 3-\alpha_{l}\right) \gamma\right]^{3}}\right)^{2} \\
&=-\frac{1}{3} \gamma\left(\sum_{l=1}^{3} \frac{1}{\left[(2 / 3) \beta+\delta+(2 / 3) \gamma-\left(1 / 3-\alpha_{l}\right) \gamma\right]^{3}}\right)^{2} \\
& \times\left[\sum_{l=1}^{3} \omega_{l}\left(\frac{1}{3}-\alpha_{l}\right)^{2}-\left(\sum_{l=1}^{3} \omega_{l}\left(\frac{1}{3}-\alpha_{l}\right)\right)^{2}\right] \\
&=-\frac{1}{3} \gamma\left(\sum_{l=1}^{3} \frac{1}{\left[(2 / 3) \beta+\delta+(2 / 3) \gamma-\left(1 / 3-\alpha_{l}\right) \gamma\right]^{3}}\right)^{2} \\
& \times \sum_{l=1}^{3} \omega_{l}\left[\left(\frac{1}{3}-\alpha_{l}\right)-\sum_{j=1}^{3} \omega_{j}\left(\frac{1}{3}-\alpha_{j}\right)\right]^{2}<0,
\end{aligned}
$$

where

$$
\begin{array}{r}
\omega_{l}=\frac{1}{\left[(2 / 3) \beta+\delta+(2 / 3) \gamma-\left(1 / 3-\alpha_{l}\right) \gamma\right]^{3}} / \\
\sum_{j=1}^{3} \frac{1}{\left[(2 / 3) \beta+\delta+(2 / 3) \gamma-\left(1 / 3-\alpha_{j}\right) \gamma\right]^{3}} .
\end{array}
$$

It follows that $C<0$, which implies that $M^{\prime} / M-D^{\prime} / D<0$. This proves part (i).

For part (ii), first note that $\lim _{\delta \rightarrow 0} \tau=\infty$ follows directly from (17). Next note that (17) implies that 


$$
\begin{aligned}
& \lim _{\delta \rightarrow 0} \delta \tau=(\beta+\gamma) x^{*} \sum_{l=1}^{3} \frac{\left(1 / 3-\alpha_{l}\right)}{\left[(2 / 3) \beta+(2 / 3) \gamma-\left(1 / 3-\alpha_{l}\right) \gamma\right]^{2}} / \\
& {\left[\frac{1}{\beta+\gamma}+\sum_{l=1}^{3} \frac{(1 / 3)(\beta+\gamma)-2\left(1 / 3-\alpha_{l}\right) \gamma}{\left[(2 / 3) \beta \delta+(2 / 3) \gamma-\left(1 / 3-\alpha_{l}\right) \gamma\right]^{2}}\right], }
\end{aligned}
$$

which is finite. This result, together with (11) and (12), then imply that $\lim _{\delta \rightarrow 0} t_{L, g}$ is finite for every majority coalition $L$ and every good $g$.

Finally, consider part (iii). We have shown in part (ii) of Proposition 1 that $\lim _{\delta \rightarrow \infty} \tau=0$. Using this result, it follows directly from equations (11) and (12) that $\lim _{\delta \rightarrow \infty} t_{L, g}=0$ for all $L$ and $g$.

\section{Proof of Proposition 4}

To prove part (i), note that-using (A3) and (A7)—we can represent (17) as

$$
\tau=\frac{(\beta+\gamma+2 \delta) x^{*} M}{\delta D} .
$$

In this representation, the capital shares $\alpha_{l}$ affect the platform only through their impact on $D$ and $M$. A direct calculation shows that

$$
\frac{\partial M}{\partial \alpha_{l}}=-\frac{(2 / 3) \beta+\delta+\left(1-\alpha_{l}\right) \gamma}{\left[(2 / 3) \beta+\delta+(2 / 3) \gamma-\left(1 / 3-\alpha_{l}\right) \gamma\right]^{3}}<0,
$$

and this expression is increasing in $\alpha_{l}$. Therefore,

$$
0>\frac{\partial M}{\partial \alpha_{j}}>\frac{\partial M}{\partial \alpha_{k}} \quad \text { for } \alpha_{j}>\alpha_{k} .
$$

Moreover,

$$
\frac{\partial D}{\partial \alpha_{l}}=2 \gamma \frac{(1 / 3)(\beta+\gamma)+\left(1 / 3-\alpha_{l}\right) \gamma}{\left[(2 / 3) \beta+\delta+(2 / 3) \gamma-\left(1 / 3-\alpha_{l}\right) \gamma\right]^{3}}>0,
$$

and this expression declines in $\alpha_{l}$. Therefore,

$$
0<\frac{\partial D}{\partial \alpha_{j}}<\frac{\partial D}{\partial \alpha_{k}} \text { for } \alpha_{j}>\alpha_{k} .
$$

It follows from these inequalities that 


$$
\frac{\partial \tau}{\partial \alpha_{j}}>\frac{\partial \tau}{\partial \alpha_{k}} \quad \text { for } \alpha_{j}>\alpha_{k} .
$$

For the proof of part (ii), first note from (18) that part (i) of this proposition immediately implies that

$$
\frac{\partial \bar{t}_{\{1,2,3\}}}{\partial \alpha_{j}}>\frac{\partial \bar{t}_{\{1,2,3\}}}{\partial \alpha_{k}} \quad \text { for } \alpha_{j}>\alpha_{k} .
$$

Next note that (19) implies that

$$
\begin{aligned}
3 \frac{\partial \bar{t}_{\{j, k\}}}{\partial \alpha_{i}}=\left[\sum_{l=1}^{3} \frac{\delta}{(2 / 3)(\beta+\gamma)+\delta-\gamma\left(1 / 3-\alpha_{l}\right)}\right] \frac{\partial \tau}{\partial \alpha_{i}} \\
-\frac{[(2 / 3)(\beta+\gamma)+\delta] x^{*}+\gamma \delta \tau}{\left[(2 / 3)(\beta+\gamma)+\delta-\gamma\left(1 / 3-\alpha_{i}\right)\right]^{2}},
\end{aligned}
$$

where the last term on the right-hand side is larger in districts with a larger $\alpha_{i}$. This observation, together with part (i) of the proposition, implies that

$$
\frac{\partial \bar{t}_{\{j, k\}}}{\partial \alpha_{q}}>\frac{\partial \bar{t}_{\{j, k\}}}{\partial \alpha_{z}} \quad \text { for all } j \neq k \text { and } \alpha_{q}>\alpha_{z} .
$$

Finally, for the proof of part (iii) note that (18) and (19) imply that

$$
\begin{aligned}
4 \frac{\partial E\left[t_{L, g}\right]}{\partial \alpha_{i}} & =\left(\frac{\delta}{\beta+\gamma+\delta}\right) \frac{\partial \tau}{\partial \alpha_{i}} \\
+ & {\left[\sum_{l=1}^{3} \frac{\delta}{(2 / 3)(\beta+\gamma)+\delta-\gamma\left(1 / 3-\alpha_{l}\right)}\right] \frac{\partial \tau}{\partial \alpha_{i}} } \\
& -\frac{[(2 / 3)(\beta+\gamma)+\delta] x^{*}+\gamma \delta \tau}{\left[(2 / 3)(\beta+\gamma)+\delta-\gamma\left(1 / 3-\alpha_{i}\right)\right]^{2}},
\end{aligned}
$$

where the last term on the right-hand side is larger in districts with a larger $\alpha_{i}$. This observation, together with part (i) of the proposition, implies that

$$
\frac{\partial E\left[t_{L, g}\right]}{\partial \alpha_{j}}>\frac{\partial E\left[t_{L, g}\right]}{\partial \alpha_{k}} \quad \text { for all } g \text { when } \alpha_{j}>\alpha_{k} .
$$

PRINCETON UNIVERSITY

HARVARD UNIVERSITY AND CIAR 


\section{REFERENCES}

Besley, Timothy, and Stephen Coate, "An Economic Model of Representative Democracy," Quarterly Journal of Economics, CXII (1997), 85-114.

Dixit, Avinash K., Gene M. Grossman, and Faruk Gul, "The Dynamics of Political Compromise," Journal of Political Economy, CVIII (2000), 531-568.

Grossman, Gene M., and Elhanan Helpman, "Party Discipline and Pork Barrel Politics," NBER Working Paper No. 11396, 2005.

Lindbeck, Assar, and Jörgen Weibull, "Balanced Budget Redistribution and the Outcome of Political Competition," Public Choice, LII (1987), 273-297.

McCarty, Nolan, Keith T. Poole, and Howard Rosenthal, "The Hunt for Party Discipline in Congress," American Political Science Review, XCV (2001), 673-687.

McGillivray, Fiona, "Party Discipline as a Determinant of the Endogenous Formation of Tariffs," American Journal of Political Science, XLI (1997), 584607.

- Privileging Industry: The Comparative Politics of Trade and Industrial Policy (Princeton, NJ: Princeton University Press, 2004).

McGillivray, Fiona, and Alastair Smith, "Institutional Determinants of Trade Policy," International Interactions, XXIII (1997), 119-143.

Milesi-Ferretti, Gian Maria, Roberto Perotti, and Massimo Rostagno, "Electoral Systems and Public Spending," Quarterly Journal of Economics, CXVII (2002), 609-657.

Osborne, Martin J., and Al Slivinski, "A Model of Political Competition with Citizen-Candidates," Quarterly Journal of Economics, CXI (1996), 65-96.

Persson, Torsten, Gerard Roland, and Guido Tabellini, "Comparative Politics and Public Finance," Journal of Political Economy, CVIII (2000), 1121-1161.

Snyder, James M., and Timothy Groseclose, "Estimating Party Influence in Congressional Role-Call Voting," American Journal of Political Science, XLIV (2000), 193-211.

Willmann, Gerald, "Why Legislators are Protectionists: The Role of Majoritarian Voting in Setting Tariffs," Christian-Albrechts-Universität zu Kiel, manuscript, 2004. 